\title{
Visible luminescence spectroscopy of free-base and zinc phthalocyanines isolated in cryogenic matrices $\dagger$
}

\author{
Ciaran Murray,,$^{a}$ Nadia Dozova, $\S^{a}$ John G. McCaffrey, ${ }^{* a}$ Niloufar Shafizadeh, ${ }^{b}$ \\ Wuthurath Chin, ${ }^{b}$ Michel Broquier ${ }^{b}$ and Claudine Crépin*b
}

Received 22nd June 2011, Accepted 11th August 2011

DOI: $10.1039 / \mathrm{c} 1 \mathrm{cp} 22039 \mathrm{j}$

The absorption, emission and excitation spectra of $\mathrm{ZnPc}$ and $\mathrm{H}_{2} \mathrm{Pc}$ trapped in $\mathrm{Ne}, \mathrm{N}_{2}, \mathrm{Ar}, \mathrm{Kr}$ and $\mathrm{Xe}$ matrices have been recorded in the region of the $\mathrm{Q}$ states. A comparison of the matrix fluorescence spectra with Raman spectra recorded in $\mathrm{KBr}$ pellets reveals very strong similarities. This is entirely consistent with the selection rules and points to the occurrence of only fundamental vibrational transitions in the emission spectra. Based on this behaviour, the vibronic modes in emission have been assigned using results obtained recently on the ground state with large basis-set DFT calculations [Murray et al. PCCP, 12, 10406 (2010)]. Furthermore, the very strong mirror symmetry between excitation and emission has allowed these assignments to be extended to the excitation (absorption) bands. While this approach works well for $\mathrm{ZnPc}$, coupling between the band origin of the $S_{2}\left(Q_{Y}\right)$ state and vibrationally excited levels of $S_{1}\left(Q_{X}\right)$, limits the range of its application in $\mathrm{H}_{2} \mathrm{Pc}$. The $\mathrm{QX}_{\mathrm{X}} / \mathrm{Q}_{\mathrm{Y}}$ state coupling is analysed from data obtained from site-selective excitation spectra, revealing pronounced matrix and site effects. From this analysis, the splitting of the $\mathrm{Q}_{\mathrm{X}}$ and $\mathrm{Q}_{\mathrm{Y}}$ states has been determined more accurately than in any previous attempts.

\section{Introduction}

As a result of considerable interest in the phthalocyanines ${ }^{1}$ (Pcs) as potential photo-conductors ${ }^{2}$ or as nonlinear materials, ${ }^{3}$ the optical properties of free-base phthalocyanine $\left(\mathrm{H}_{2} \mathrm{Pc}\right)$ and zinc phthalocyanine $(\mathrm{ZnPc})$ have been studied in a wide range of environments. Thus the electronic spectroscopy of both molecules have been reported in the gas phase, ${ }^{4,5}$ in low-temperature jets, ${ }^{6-8}$ in He droplets ${ }^{9,10}$ and in thin films. ${ }^{11}$ The two molecules have also been studied in cryogenic matrices: either in Shpol'skii organic matrices ${ }^{12-14}$ or isolated in the solid rare gases. ${ }^{15-18}$ In a detailed magnetic circularly polarised luminescence (MCPL) study of $\mathrm{ZnPc}$, Schatz and co-workers ${ }^{19}$ identified the presence of both crystal field splitting and Jahn-Teller coupling on the degenerate first excited singlet state. IR and Raman spectra for $\mathrm{H}_{2} \mathrm{Pc}$ in thin films ${ }^{20}$ and for $\mathrm{ZnPc}$ in $\mathrm{KBr}$ discs ${ }^{21}$ have been presented and theoretical predictions for both molecules have

\footnotetext{
${ }^{a}$ Department of Chemistry, National University of Ireland-

Maynooth, Co. Kildare, Ireland.E-mail: john.mccaffrey@nuim.ie

${ }^{b}$ Institut des Sciences Moléculaires d'Orsay UMR 8214 -

Univ. Paris-Sud, CNRS, Orsay, F-91405 France.

E-mail: claudine.crepin-gilbert@u-psud.fr

$\dagger$ Electronic supplementary information (ESI) available. See DOI: 10.1039/c1cp22039j

$\ddagger$ Present address: Tyndall National Institute, University College Cork, "Lee Maltings", Dyke Parade, Cork, Ireland.

$\S$ Present address: Laboratoire P.A.S.T.E.U.R. -UMR 8640, Ecole Normale Superieure, Paris, France.
}

also been published. ${ }^{22,23}$ Recently we have used the matrixisolation technique to obtain vibrational signatures of both molecules, ${ }^{24}$ free of spectral complexities due to aggregates. With the input of large basis-set density functional theory (DFT) calculations, we have achieved a comprehensive vibrational analysis ${ }^{24}$ of the matrix spectra of both molecules.

In contrast to the porphyrins, the transition between the ground state $\mathrm{G}\left(\mathrm{S}_{0}\right)$ and the first excited singlet $\mathrm{Q}\left(\mathrm{S}_{1}\right)$ state is fully allowed in the phthalocyanines. This transition is responsible for the intense Q-band absorption in the red part of the spectrum. For a molecule like $\mathrm{ZnPc}$ with $D_{4 h}$ symmetry, the $\mathrm{S}_{1}$ state is degenerate, while in $\mathrm{H}_{2} \mathrm{Pc}$, having $D_{2 h}$ symmetry, the degeneracy is lifted and two states arise-labelled the $\mathrm{Q}_{\mathrm{X}}\left(\mathrm{S}_{1}\right)$ at lower energy and the $\mathrm{Q}_{\mathrm{Y}}\left(\mathrm{S}_{2}\right)$ at higher energy. The resulting strong absorption in the $600-850 \mathrm{~nm}$ range- the so-called therapeutic body window-renders the phthalocyanines especially relevant for medical applications as photosensitisers in laser cancer therapy. ${ }^{25}$

The most recent laser-induced fluorescence (LIF) investigation of zinc and free-base phthalocyanine made under jet-cooled conditions has been reported by Plows and Jones. ${ }^{6}$ In spite of numerous gas phase studies of $\mathrm{H}_{2} \mathrm{Pc}$, the band origin of the $\mathrm{Q}_{\mathrm{Y}}\left(\mathrm{S}_{2}\right)$ state has still not been conclusively determined. This is due to the spectral complexity which arises from the coupling between the band origin of the $\mathrm{Q}_{\mathrm{Y}}\left(\mathrm{S}_{2}\right)$ state and the high frequency modes of the $\mathrm{Q}_{\mathrm{x}}\left(\mathrm{S}_{1}\right)$ state. Matrix-isolation spectroscopy affords an ideal opportunity to identify the true band 


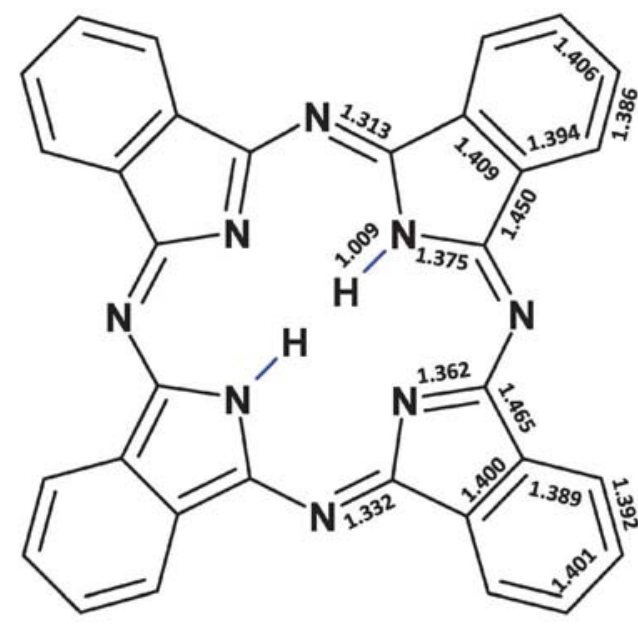

$\mathrm{H}_{2} \mathrm{Pc}, \mathrm{D}_{2 \mathrm{~h}}$

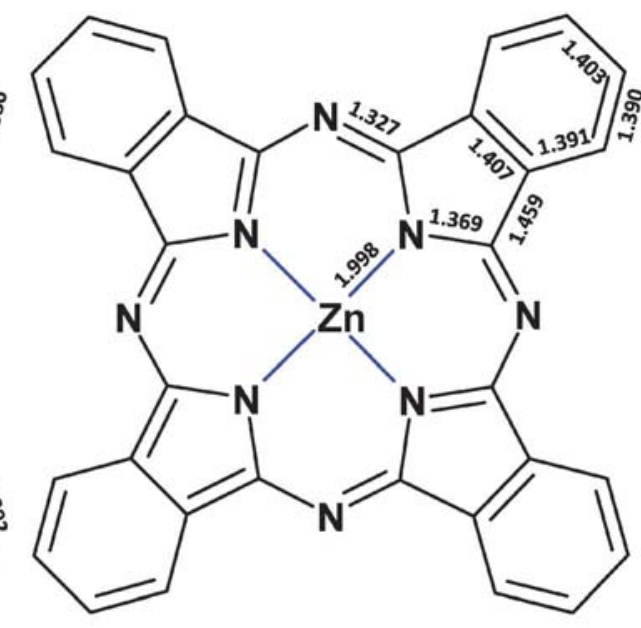

$\mathrm{ZnPc}, \mathrm{D}_{4 \mathrm{~h}}$

Fig. 1 Structures of $\mathrm{ZnPc}\left[D_{4 h}\right]$ and $\mathrm{H}_{2} \mathrm{Pc}\left[D_{2 h}\right]$ determined by the recent large basis-set DFT calculations presented in ref. 24 .

origin since spectra recorded under these conditions are free of any rotational structure and solvent-shifts induced by the solid rare gases, while present, are small and can be used to monitor the effect of matrix shifts on the $\mathrm{Q}_{\mathrm{X}} / \mathrm{Q}_{\mathrm{Y}}$ state couplings. Since the density of vibrational levels in $\mathrm{Q}_{\mathrm{X}}\left(\mathrm{S}_{1}\right)$ is not very high in the region $1000 \mathrm{~cm}^{-1}$ above its origin, the coupling can vary strongly as a function of the host matrix. Because of slightly different shifts, it may also be dependent on the site occupied in a given host solid and will also be sensitive to isotopic substitution. For the aforementioned reasons, we undertook an investigation of the visible spectroscopy of $\mathrm{H}_{2} \mathrm{Pc}$ and $\mathrm{ZnPc}$ isolated in inert, low temperature solids.

While $\mathrm{H}_{2} \mathrm{Pc}$ belongs to the $D_{2 h}$ symmetry point group and $\mathrm{ZnPc}$ belongs to $D_{4 h}$, both molecules are expected to have very similar geometries. As shown in Fig. 1, the structures determined by us in recent DFT calculations ${ }^{24}$ confirm these expectations where the geometry optimised structures are presented for both molecules. The DFT calculations were conducted with the B3LYP functional and the large $6-311++G(2 d, 2 p)$ basis set was used to predict the infrared and Raman frequencies. Complete details of the molecular parameters for both $\mathrm{H}_{2} \mathrm{Pc}$ and $\mathrm{ZnPc}$ were provided in Table S1 of the supplementary material in ref. 24 while the predicted IR and Raman frequencies were given in Table S2.

Visible absorption spectra of $\mathrm{H}_{2} \mathrm{Pc}$ and $\mathrm{ZnPc}$ isolated in a variety of matrices were first reported by Bajema et al. ${ }^{17}$ A detailed lineshape analysis of $\mathrm{H}_{2} \mathrm{Pc}$ in $\mathrm{Ar}$ has been presented by Geissinger et al. ${ }^{26}$ The emission and excitation spectra of $\mathrm{H}_{2} \mathrm{Pc}$ have been studied in $\mathrm{Ar}$ matrices by Bondybey and English. ${ }^{18}$ In contrast, the $\mathrm{Ne}$ and $\mathrm{N}_{2}$ systems have not yet received much attention. Like the porphyrins, the phthalocyanines have a propensity of forming aggregates in more concentrated matrix samples. As demonstrated in the systematic matrix study of Williamson and co-workers ${ }^{16}$ on $\mathrm{ZnPc}$, such species absorb to the red of the sharp $0-0$ monomer Q state transitions. The content of aggregate species was kept to a minimum in the samples prepared in the present study. Accordingly, the absorption and emission spectra recorded herein correspond to samples containing well-isolated guest molecules.
In an earlier study conducted by $\mathrm{us}^{27}$ it was noticed that one particular vibronic mode in the emission spectra of both $\mathrm{ZnPc}$ and $\mathrm{H}_{2} \mathrm{Pc}$ exhibited very efficient stimulated emission (SE) when isolated in low temperature matrices and excited with a pulsed dye laser. The modes concerned were located at 1550 and $1525 \mathrm{~cm}^{-1}$ in $\mathrm{H}_{2} \mathrm{Pc}$ and $\mathrm{ZnPc}$ respectively in $\mathrm{Ar}$ matrices. With increased laser intensity or in more concentrated samples, lower frequency modes also produced SE. The emission bands exhibiting this behaviour will be analysed in the present work to achieve vibrational assignments.

In the present paper we describe a study of the absorption and luminescence spectra of $\mathrm{ZnPc}$ and $\mathrm{H}_{2} \mathrm{Pc}$ isolated in rare gas and nitrogen matrices in the region of the $\mathrm{Q}$ band. Very strong similarities were noted in our earlier study ${ }^{24}$ between the vibrational structure in Raman and emission spectra. A key aspect of the present work is the exploitation of vibrational analysis ${ }^{24}$ of Raman spectra, presented in ref. 24, to obtain assignments for the emission bands. Due to the strong mirror symmetry between emission and excitation spectra, an opportunity thereby exists to also achieve vibrational assignments for the multiple lines present in the excitation spectroscopy of the phthalocyanines. Moreover, detailed comparison of the recorded excitation and emission spectra aids considerably in the identification of the true band origin in the region of the onset of the $\mathrm{Q}_{\mathrm{Y}}\left(\mathrm{S}_{2}\right)$ excited state of $\mathrm{H}_{2} \mathrm{Pc}$ since the complicated excitation bandshapes presented in this spectral region can be isolated and then analysed.

\section{Experimental}

Experiments on free-base $\left(\mathrm{H}_{2} \mathrm{Pc}\right)$ and zinc $(\mathrm{ZnPc})$ phthalocyanines were undertaken at both the Institut des Sciences Moléculaires d'Orsay (ISMO) at Orsay and by the Low Temperature Spectroscopy (LTS) group at NUI-Maynooth. $\mathrm{ZnPc}$ and $\mathrm{H}_{2} \mathrm{Pc}$ were purchased from Sigma Aldrich and Fluka respectively and used without further purification. Matrix samples were prepared by resistive heating of the phthalocyanines to around $350{ }^{\circ} \mathrm{C}$ using the flowing host gas

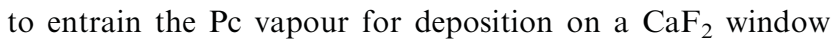


(sapphire at Orsay) at cryogenic temperatures. The oven design $^{28}$ used in both experiments has been described recently. The cryogenic set-ups used differ only in the minimum temperatures attainable with a base value of $7 \mathrm{~K}$ possible at Orsay while it is $13 \mathrm{~K}$ at Maynooth. Large gas flows $(40 \mathrm{mmol} / \mathrm{h})$ for a period of approximately 30 mins were required to achieve isolation of phthalocyanine $(\mathrm{Pc})$ as a monomer for samples used to record visible spectroscopy. The isolation condition of the Pcs in matrices was monitored with absorption in the red region of the visible spectrum. For this a tungsten lamp source was used.

Luminescence (emission-excitation) spectra were recorded using tuneable dye lasers - either a home-built system at Orsay or the Quantel TDL90 system at Maynooth. The dyes DCM and LDS698 were used to cover the spectral ranges 625-660 $\mathrm{nm}$ and 665-685 $\mathrm{nm}$ respectively. Both systems are pumped by the second harmonic of nanosecond Q-switched Nd:YAG lasers that have been described previously. ${ }^{29,30}$ Emission was recorded with the Andor DH720 intensified, time-gated charge coupled device (iCCD) detector system. Absorption and emission spectra were recorded on a $0.6 \mathrm{~m}$ Jobin-Yvon monochromator at Orsay (resolution of few $\mathrm{cm}^{-1}$ ), while a $0.5 \mathrm{~m}$ Acton Research SP500i monochromator was used at Maynooth. Excitation spectra were recorded by varying the laser wavelength while monitoring a range of emission wavelengths with the iCCD camera. This technique allowed us to record high-resolution excitation spectra of several emission bands simultaneously. The resulting total luminescence, when presented in the form of 2D excitation-emission matrices (EEM) plots, provides a very powerful method of resolving complex site occupancy. No correction, including the spectral sensitivity of the detection system, was applied to the spectral data.

\section{Results}

\section{Visible absorption}

The absorption spectra of $\mathrm{ZnPc}$ in all matrices are dominated, as shown on the left panel in Fig. 2, by the intense $0-0$ transition of the $\mathrm{Q}$ band. The band maximum of this transition has been observed in the gas phase under bulb $b^{5}$ conditions at $15128 \mathrm{~cm}^{-1}$ while the band origin has been identified at $15702.9 \mathrm{~cm}^{-1}$ in liquid helium droplets ${ }^{10}$ and at $15766 \mathrm{~cm}^{-1}$ in free jet ${ }^{6}$ conditions. The last value is indicated by the dashed vertical line in Fig. 2. The $0-0$ transition of the $\mathrm{Q}$ band is situated at 15574 , $15328,15309,15182$ and $15035 \mathrm{~cm}^{-1}$ in $\mathrm{Ne}, \mathrm{N}_{2}, \mathrm{Ar}, \mathrm{Kr}$ and $\mathrm{Xe}$ respectively. These bands are all red-shifted from the gas phase position and the energy of the transition decreases from $\mathrm{Ne}$ to Xe when the interaction with the matrix gets stronger. Thus the largest shift from the gas phase has been observed in Xe with a value of $731 \mathrm{~cm}^{-1}$ while the smallest is $192 \mathrm{~cm}^{-1}$ in neon. It is only $63 \mathrm{~cm}^{-1}$ in helium droplets. ${ }^{10}$ Other vibronic bands of lower intensity are evident in the region from 15500 to $17000 \mathrm{~cm}^{-1}$. The spectra in $\mathrm{Ne}$ and $\mathrm{N}_{2}$ have been recorded at $8 \mathrm{~K}$ and these matrices, especially $\mathrm{N}_{2}$, exhibit resolved site structure. The absorption spectra in $\mathrm{Ar}, \mathrm{Kr}$ and $\mathrm{Xe}$ were recorded at higher temperature $(13 \mathrm{~K})$ and while the bands are broader, they do show resolved features in laser excitation scans.

In contrast to $\mathrm{ZnPc}$, the absorption spectra of $\mathrm{H}_{2} \mathrm{Pc}$ recorded at $8 \mathrm{~K}$, appear more complex and structured as

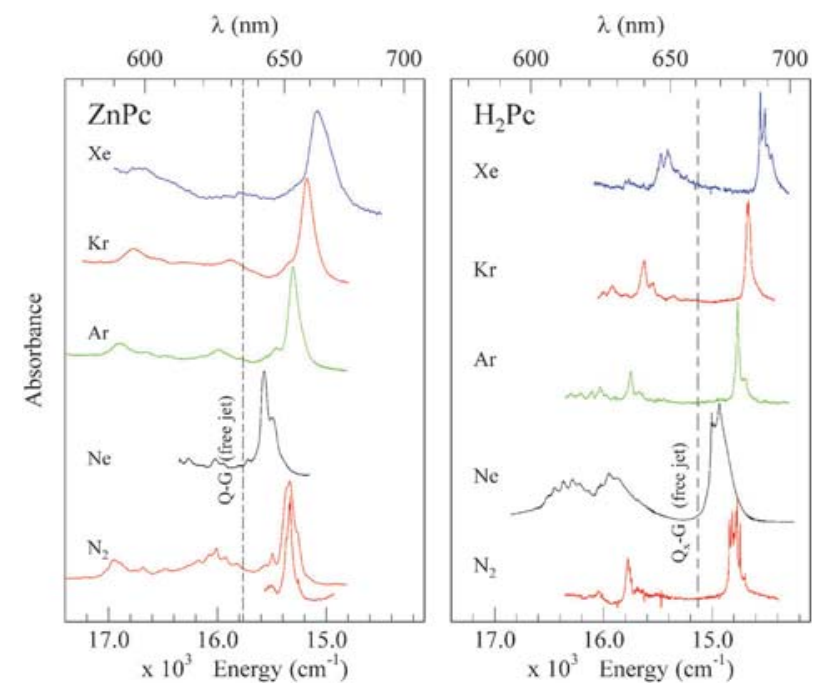

Fig. 2 Absorption spectra of $\mathrm{ZnPc}$ (left panel) and $\mathrm{H}_{2} \mathrm{Pc}$ (right panel) trapped in $\mathrm{Ne}, \mathrm{N}_{2}, \mathrm{Ar}, \mathrm{Kr}$ and Xe solids. All the spectra were recorded at $8 \mathrm{~K}$ except for $\mathrm{ZnPc}$ in $\mathrm{N}_{2}, \mathrm{Ar}, \mathrm{Kr}$ and $\mathrm{Xe}$ which were recorded at $13 \mathrm{~K}$. The lower trace presented for $\mathrm{ZnPc}$ in $\mathrm{N}_{2}$ was recorded at $8 \mathrm{~K}$. The locations of the gas phase band origins which are accurately known from jet experiments are indicated by the dashed vertical lines.

shown on the right in Fig. 2. In addition, two principal features are evident in the spectra recorded in all samples corresponding to absorptions of the $\mathrm{Q}_{\mathrm{X}}$ and $\mathrm{Q}_{\mathrm{Y}}$ states. The band origin of the $\mathrm{Q}_{\mathrm{X}}\left(\mathrm{S}_{1}\right) \leftarrow \mathrm{G}\left(\mathrm{S}_{0}\right)$ transition is known from laser excitation spectroscopy ${ }^{7}$ done in jets to be $15132 \mathrm{~cm}^{-1}$ in the gas phase and at $15088.9 \mathrm{~cm}^{-1}$ in helium droplets. ${ }^{10}$ The absorption values recorded in all the matrices studied are collected in Table 1 as well as the matrix shifts. As indicated in Fig. 2 a red-shift exists in all matrices - it is smallest in $\mathrm{Ne}$ $\left(198 \mathrm{~cm}^{-1}\right)$ and largest in $\mathrm{Xe}\left(573 \mathrm{~cm}^{-1}\right)$. The $\mathrm{Q}_{\mathrm{Y}}-\mathrm{Q}_{\mathrm{X}}$ splitting is also host dependent, decreasing from $\mathrm{Ne}$ to $\mathrm{Xe}$. In fact, the $Q_{Y}-G$ transition energy is reduced by a very similar fraction as the $Q_{X}-G$ transition energy in the different matrices (see Table 1).

In yet further contrast to $\mathrm{ZnPc}$, the shapes of the $\mathrm{H}_{2} \mathrm{Pc}$ bands differ markedly from one solid to another with a highly structured band present in $\mathrm{N}_{2}$ and a broad but structured band in Ne. Ar presents the simplest absorption spectrum with a single dominating feature. However, as revealed in laser excitation spectroscopy, the widths of the bands in all matrices arise from occupancy of the $\mathrm{H}_{2} \mathrm{Pc}$ or $\mathrm{ZnPc}$ molecules in multiple sites. However, in the case of $\mathrm{H}_{2} \mathrm{Pc} / \mathrm{N}_{2}$, the resolved lines of the structured absorption band are very narrow and could arise from distinct sites. Their linewidths $\left(4\right.$ to $\left.5 \mathrm{~cm}^{-1}\right)$ are close to the resolving power of the recording instruments, $\sim 2 \mathrm{~cm}^{-1}$ in this case.

When isolated in solids, free-base phthalocyanine can exist in two distinct tautomeric forms which differ depending on the position of the two hydrogen atoms on the inner ring of the $\mathrm{H}_{2} \mathrm{Pc}$ molecule. Because of the interaction with the host matrix, these two tautomers are known from existing matrix work $^{31}$ on free-base porphine to have different absorption frequencies. Thus, where only one band appears in the $\mathrm{ZnPc}$ absorption spectrum, two are expected for $\mathrm{H}_{2} \mathrm{Pc}$. This fact can explain why some of the absorptions peaks of free-base 
Table 1 Absorption values in wavenumbers $\left(\mathrm{cm}^{-1}\right)$ units for the band origins of $\mathrm{ZnPc}\left(\mathrm{Q}\right.$ band) and $\mathrm{H}_{2} \mathrm{Pc}\left(\mathrm{Q}_{\mathrm{X}}\right)$ in different matrices as determined from the band maxima. The gas phase band origins are from the published data of Fitch et al. [ref. 7] for $\mathrm{H}_{2} \mathrm{Pc}$ and from Plows and Jones [ref. 6] for $\mathrm{ZnPc}$. The splitting of the $\mathrm{Q}_{\mathrm{X}}$ and $\mathrm{Q}_{\mathrm{Y}}$ matrix bands of $\mathrm{H}_{2} \mathrm{Pc}$ determined in this way (from absorption spectra) are only rough indicators of the splitting. Much more precise, site specific values emerge from a detailed analysis of site-resolved excitation data discussed in Section IV.C.2. The helium data is from the work of Lehning et al. [ref. 10], while the Shpol'skii data is that of Huang et al. [ref. 13]. The gas phase and liquid helium splittings quoted (highlighted by asterisks) are estimates based on band assignments emerging in the analysis conducted in the present study

\begin{tabular}{|c|c|c|c|c|c|c|}
\hline & \multirow[b]{2}{*}{$\mathrm{Q}_{\mathrm{x}}$} & \multicolumn{3}{|l|}{$\mathrm{H}_{2} \mathrm{Pc}$} & \multicolumn{2}{|l|}{$\mathrm{ZnPc}$} \\
\hline & & $\begin{array}{l}\text { Matrix } \\
\text { shift }\end{array}$ & $\mathrm{Q}_{\mathrm{Y}}$ & $\begin{array}{l}\mathrm{Q}_{\mathrm{Y}}-\mathrm{QX}_{\mathrm{X}} \\
\text { Splitting }\end{array}$ & Q & $\begin{array}{l}\text { Matrix } \\
\text { shift }\end{array}$ \\
\hline Free jet & 15132 & & (16 188) & $1056^{*}$ & 15766 & \\
\hline $\mathrm{Ne}$ & 14934 & -198 & 15951 & 1017 & 15574 & -192 \\
\hline $\mathrm{N}_{2}$ & 14773 & -359 & 15775 & 1002 & 15328 & -428 \\
\hline $\mathrm{Ar}$ & 14768 & -364 & 15753 & 985 & 15309 & -457 \\
\hline $\mathrm{Kr}$ & $\begin{array}{l}14685 \\
14670\end{array}$ & -447 & $\begin{array}{l}15655 \\
15624\end{array}$ & 970 & 15182 & -584 \\
\hline $\mathrm{Xe}$ & $\begin{array}{l}14559 \\
14518\end{array}$ & -573 & $\begin{array}{l}15475 \\
15412\end{array}$ & 916 & 15035 & -731 \\
\hline $\mathrm{He}$ & 15089 & -43 & $(-)$ & $1056^{*}$ & 15703 & -63 \\
\hline Shpol'skii & $\begin{array}{l}14475 \\
14411\end{array}$ & $\begin{array}{l}-657 \\
-721\end{array}$ & $\begin{array}{l}15332 \\
15275\end{array}$ & $\begin{array}{l}857 \\
864\end{array}$ & $\begin{array}{l}14914 \\
14885\end{array}$ & $\begin{array}{l}-852 \\
-881\end{array}$ \\
\hline
\end{tabular}

phthalocyanine do not exist in the spectrum of the metallophthalocyanine, especially in $\mathrm{N}_{2}$.

\section{Emission spectra}

Only emission corresponding to transitions from $\mathrm{v}^{\prime}=0$ in the first excited state $\left[\mathrm{Q}\left(\mathrm{S}_{1}\right)\right.$ or $\mathrm{Qx}_{\mathrm{X}}\left(\mathrm{S}_{1}\right)$ in the case of $\mathrm{ZnPc}$ or $\mathrm{H}_{2} \mathrm{Pc}$ respectively] to various vibrational levels $\mathrm{v}^{\prime \prime}$ in the ground $\mathrm{G}\left(\mathrm{S}_{0}\right)$ electronic state was observed. Thus in the case of both molecules vibrationally relaxed emission occurs. In addition, similar emission was observed with laser excitation in the $\mathrm{Q}_{\mathrm{X}}$ or $\mathrm{Q}_{\mathrm{Y}}$ states of $\mathrm{H}_{2} \mathrm{Pc}$ revealing that the non-radiative relaxation from $\mathrm{Q}_{\mathrm{Y}}$ to $\mathrm{Q}_{\mathrm{X}}$ is much faster than the $\sim 1$ ns timescale of our experiment. The phonon broadened emission bands recorded for $\mathrm{ZnPc}$ in the present study, preclude a detailed analysis of either Jahn-Teller distortions or crystal field splitting in the excited state.

Fig. 3 provides a comparison of the emission spectra recorded for $\mathrm{ZnPc}$ and $\mathrm{H}_{2} \mathrm{Pc}$ in an Ar matrix. Both molecules show a well-resolved vibronic structure extending from 0 to $1600 \mathrm{~cm}^{-1}$ from the origin of the electronic transition. It is evident that the emission spectra of the two molecules exhibit many similarities, especially the vibronic progression consisting of three dominant bands in the red part (1100 to $1500 \mathrm{~cm}^{-1}$ shifted from the origin) of the spectrum. The frequencies of the emission bands of $\mathrm{ZnPc}$ recorded in different solids are collected in Table 2, while they are given in Table 3 for $\mathrm{H}_{2} \mathrm{Pc}$ in the same solids. For each species, the fluorescence intensity distribution of the vibronic structure is the same in all the matrices (and all the families of sites). It is also evident in Fig. 3 that the $0-0$ transition dominates the emission intensity by more than a factor of 10 . This is consistent with the results of measurements made in low temperature molecular beams ${ }^{6,7}$

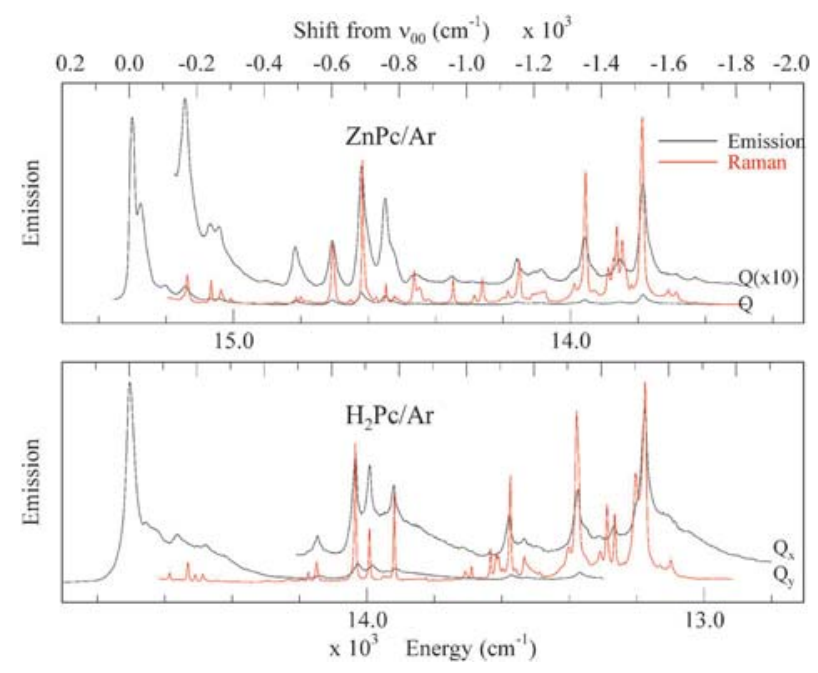

Fig. 3 A comparison of the fluorescence and Raman spectra of $\mathrm{ZnPc}$ (upper panel) and $\mathrm{H}_{2} \mathrm{Pc}$ (lower panel) revealing the very strong similarities between the emission and Raman spectra. Emission spectra of $\mathrm{ZnPc} / \mathrm{Ar}$ were excited in the $\mathrm{Q}$ band at $\lambda=647.2 \mathrm{~nm} . \mathrm{H}_{2} \mathrm{Pc} / \mathrm{Ar}$ was excited in $\mathrm{Q}_{\mathrm{Y}}$ at $\lambda=637.9 \mathrm{~nm}$ and excited in $\mathrm{Q}_{\mathrm{X}}$ at $\lambda=678.9 \mathrm{~nm}$. The scale on the top of both plots shows the emission energies as a shift from the position of the $0-0$ transition. Conventional Raman spectra of $\mathrm{ZnPc}$ and $\mathrm{H}_{2} \mathrm{Pc}$ in $\mathrm{KBr}$ pellets are shown by the red trace (ref. 24).

Table 2 Frequencies (in $\mathrm{cm}^{-1}$ ) of the vibrational levels of ground state $\left[\mathrm{G}\left(\mathrm{S}_{0}\right)\right] \mathrm{ZnPc}$ as measured in emission for different matrices. The Shpol'skii data is from Huang et al. [ref. 13] while the symmetry attributions are from ref. 24

\begin{tabular}{lrrrrlll}
\hline $\mathrm{Ne}$ & $\mathrm{N}_{2}$ & \multicolumn{1}{c}{$\mathrm{Ar}$} & $\mathrm{Kr}$ & $\mathrm{Xe}$ & & Shpol'skii & $\mathrm{DFT}$ \\
\hline & 21 & 34 & 79 & & $\mathrm{w}$ & & \\
& 104 & 102 & 104 & 102 & $\mathrm{w}$ & 125 & $\mathrm{~B}_{2 \mathrm{~g}}$ \\
& 163 & 161 & 161 & 161 & $\mathrm{~m}$ & & $\mathrm{~B}_{1 \mathrm{~g}}$ \\
& 227 & 237 & 237 & & $\mathrm{w}$ & 232 & $\mathrm{~B}_{2 \mathrm{~g}}$ \\
& 262 & 260 & 260 & 265 & $\mathrm{w}$ & & $\mathrm{A}_{1 \mathrm{~g}}$ \\
495 & 488 & 490 & 491 & 488 & $\mathrm{~m}$ & 482 & $\mathrm{~B}_{2 \mathrm{~g}}$ \\
& & & & & & 536 & $\mathrm{~B}_{1 \mathrm{~g}}$ \\
$595(\mathrm{~s})$ & 597 & 598 & 598 & & $\mathrm{~m}$ & 592 & $\mathrm{~A}_{1 \mathrm{~g}}$ \\
673 & 683 & 689 & 689 & & $\mathrm{~s}$ & 681 & $\mathrm{~A}_{1 \mathrm{~g}}$ \\
751 & 752 & 751 & 751 & & $\mathrm{~s}$ & 750 & $\mathrm{~B}_{1 \mathrm{~g}}$ \\
841 & 845 & 845 & 845 & & $\mathrm{~m}$ & 836 & $\mathrm{~A}_{1 \mathrm{~g}}$ \\
956 & 945 & 945 & 945 & 954 & $\mathrm{w}$ & 950 & $\mathrm{~B}_{2 \mathrm{~g}}$ \\
1151 & 1147 & 1150 & 1149 & 1152 & $\mathrm{~m}$ & 1143 & $\mathrm{~B}_{1 \mathrm{~g}}$ \\
& 1215 & 1221 & 1221 & 1223 & $\mathrm{w}$ & & $\mathrm{B}_{2 \mathrm{~g}}$ \\
1346 & 1346 & 1346 & 1346 & 1350 & $\mathrm{~s}$ & 1342 & $\mathrm{~A}_{1 \mathrm{~g}} / \mathrm{B}_{1 \mathrm{~g}}$ \\
1451 & 1448 & 1448 & 1448 & 1452 & $\mathrm{~m}$ & & $\mathrm{~B}_{1 \mathrm{~g}}$ \\
1519 & 1525 & 1525 & 1524 & 1522 & $\mathrm{~s}$ & 1518 & $\mathrm{~B}_{1 \mathrm{~g}}$ \\
1614 & - & 1624 & 1610 & 1613 & $\mathrm{w}$ & & $\mathrm{B}_{2 \mathrm{~g}}$ \\
\hline
\end{tabular}

in which the $0-0$ transition was found to carry most of the Franck-Condon intensity.

When the laser excitation frequency is tuned inside the $0-0$ band of the first excited state, the emission spectra show slight changes in terms of frequency shifts and the shapes of the vibronic bands. This is due to multiple site occupancy. Nevertheless, the fluorescence line narrowing effect is not strong because of a non-negligible coupling with the lattice phonons. In the case of $\mathrm{ZnPc}$, two or three main families of sites are thus detected in all the matrices. Similarly, a limited number of families of sites were observed for $\mathrm{H}_{2} \mathrm{Pc}$, except in solid nitrogen where the number of clearly distinct families of 
Table 3 Frequencies (in $\mathrm{cm}^{-1}$ ) of the vibrational levels of ground state $\left[\mathrm{G}\left(\mathrm{S}_{0}\right)\right] \mathrm{H}_{2} \mathrm{Pc}$ measured in emission for different matrices. The Shpol'skii data are from Huang et al. [ref. 13] and the gas data from Fitch et al. [ref. 8]. The symmetry attributions are from ref. 24

\begin{tabular}{|c|c|c|c|c|c|c|c|c|}
\hline Gas phase & $\mathrm{Ne}$ & $\mathrm{N}_{2}$ & $\mathrm{Ar}$ & $\mathrm{Kr}$ & $\mathrm{Xe}$ & & Shpol'skii & DFT \\
\hline 132 & & - & 140 & 143 & - & $\mathrm{m}$ & 136 & $A_{g}$ \\
\hline 184 & & - & 190 & - & - & vw & 184 & $\mathrm{~B}_{1 \mathrm{~g}}^{\mathrm{g}}$ \\
\hline 231 & & - & 238 & 238 & - & vw & 232 & $\mathrm{~A}_{\mathrm{g}}$ \\
\hline 484 & & - & 489 & 494 & - & vw & 487 & $\mathrm{~B}_{1 \mathrm{~g}}$ \\
\hline 544 & & - & - & 544 & - & vw & 542 & $\mathrm{~A}_{\mathrm{g}}$ \\
\hline 574 & & 574 & 576 & 576 & 572 & w & 569 & $\mathrm{~A}_{\mathrm{g}}$ \\
\hline 685 & $688 w$ & 687 & 688 & 688 & 682 & $\mathrm{~s}$ & 683 & $A_{g}$ \\
\hline 729 & 726 & 731 & 730 & 731 & 727 & $\mathrm{~s}$ & 725 & $A_{g}$ \\
\hline 768 & & - & - & 771 & - & $\mathrm{vw}$ & 769 & $A_{g}$ \\
\hline 799 & & 802 & 802 & 802 & 800 & $\mathrm{~m}$ & 801 & $A_{g}$ \\
\hline 1012 & & - & - & - & 965 & vw & 1009 & $A_{g}$ \\
\hline 1037 & & - & - & 1031 & 1030 & vw & 1030 & $\mathrm{~B}_{1 \mathrm{~g}}$ \\
\hline 1111 & $1070 \mathrm{~m}$ & - & - & - & 1090 & vw & 1107 & $B_{1 g}$ \\
\hline 1144 & 1148 & - & 1145 & 1145 & 1143 & $\mathrm{~m}$ & 1141 & $A_{g}$ \\
\hline 1189 & & - & 1188 & 1190 (br.sh) & 1184 & $\mathrm{w}$ & $1183 / 1188$ & $\mathrm{~A}_{\mathrm{g}}$ and/or $\mathrm{B}_{1 \mathrm{~g}}$ \\
\hline 1233 & & - & - & - & 1253 & vw & 1233 & $B_{1 g}$ \\
\hline 1346 & & 1356 & 1350 & 1351 & 1350 & $\mathrm{~s}$ & 1352 & $\mathrm{~A}_{\mathrm{g}}$ \\
\hline 1375 & 1383 & - & - & - & 1376 & $\mathrm{vW}$ & 1372 & $A_{g}$ \\
\hline 1456 & 1472 & 1460 & 1456 & 1456 & 1456 & $\mathrm{w}$ & 1453 & $A_{g}$ \\
\hline \multirow[t]{2}{*}{1517} & & - & 1523 & - & - & $\mathrm{vW}$ & 1522 & $A_{g}$ \\
\hline & 1535 & - & - & - & - & & $1542 / 1546$ & $\mathrm{~A}_{\mathrm{g}}$ and/or $\mathrm{B}_{1 \mathrm{~g}}$ \\
\hline 1545 & 1547 & 1553 & 1550 & 1550 & 1554 & $\mathrm{~s}$ & 1555 & $A_{g}$ \\
\hline
\end{tabular}

sites is larger. However, while the $\mathrm{Q}_{\mathrm{X}}$ state provides good site selective excitation, with narrow emission bands, excitation of the $Q_{Y}$ state results in a much poorer site selection, as evident in emission by a broadening of bands in Ar (shown by the lower black trace in Fig. 3) or an additional structure involving multiple sites in nitrogen. This effect arises as a result of the spectral overlap of the absorption bands of the two electronic states in $\mathrm{H}_{2} \mathrm{Pc}$ in this region.

\section{Time-resolved emission}

A summary of the emission decay curves recorded for $\mathrm{H}_{2} \mathrm{Pc}$ and $\mathrm{ZnPc}$ isolated in different solids $\left(\mathrm{N}_{2}, \mathrm{Ar}, \mathrm{Kr}\right.$ and $\left.\mathrm{Xe}\right)$ is given in Fig. 4. The fluorescence decay curves were measured with time-gated iCCD detection and the lifetimes extracted by single exponential fits. From the timescales indicated in Fig. 4, the fluorescence lifetimes of $\mathrm{H}_{2} \mathrm{Pc}$ are significantly longer than those of $\mathrm{ZnPc}$. Thus the lifetimes of free base phthalocyanine are 12, 13, 13, 8 and 2.7 ns for $\mathrm{Ne}, \mathrm{N}_{2}, \mathrm{Ar}, \mathrm{Kr}$ and $\mathrm{Xe}$ respectively, while the lifetimes measured for $\mathrm{ZnPc}$ in $\mathrm{N}_{2}, \mathrm{Ar}$ and $\mathrm{Kr}$ all have very similar values around 3 ns. With an experimental uncertainty of $\pm 1 \mathrm{~ns}$, the decay times in the lighter rare gases and nitrogen all agree and from their lack of temperature dependence, are not affected by any non-radiative relaxation induced by the matrix environment. These values are consistent with the lifetimes observed for porphyrins, such as zinc and free-base tetraphenyl porphine (ZnTPP and $\mathrm{H}_{2}$ TPP) in the gas phase. ${ }^{32}$ The fluorescence lifetimes of $\mathrm{H}_{2} \mathrm{Pc}$ and $\mathrm{ZnPc}$ are shortest in $\mathrm{Xe}(\sim 2.8 \mathrm{~ns})$ and $\mathrm{Kr}(8 \mathrm{~ns})$, probably due to the competitive, non-radiative $S_{1} \rightarrow T_{1}$ intersystem crossing - a transition enhanced in the heavier host solids. Attempts to observe the phosphorescence, predicted to occur in the near infrared (NIR), from the triplet states of $\mathrm{H}_{2} \mathrm{Pc}$ and $\mathrm{ZnPc}$ in $\mathrm{Xe}$ with dye laser excitation of the $\mathrm{Q}$ state proved unsuccessful using both FT-NIR interferometer and NIR diode array dispersive detection methods.

\section{Excitation spectra}

The excitation spectra recorded for the phthalocyanines provide more highly resolved bands than what has been achieved in previous absorption studies. The results obtained for $\mathrm{ZnPc}$ and $\mathrm{H}_{2} \mathrm{Pc}$ isolated in different matrices are shown in Fig. 5 and 6 respectively. To facilitate easy comparison of the data recorded in different environments, all the spectra presented are shown as the shift from the band origin $\left(\nu_{0-0}\right)$ of the $\mathrm{Q}_{\mathrm{X}}$ state. The energies of the different modes of $\mathrm{ZnPc}$ for the major sites in $\mathrm{Ar}, \mathrm{Kr}, \mathrm{Xe}$ and $\mathrm{N}_{2}$ (calculated as the shift from the band origin) are collected in Table 4 and compared with Shpol'skii matrix ${ }^{13}$ and gas phase data. ${ }^{6}$ The energies of the different vibronic modes observed for $\mathrm{H}_{2} \mathrm{Pc}$ are collected in Table 5 and compared with Shpol'skii matrix ${ }^{13}$ and gas phase data. $^{6,7}$

The excitation spectra for $\mathrm{ZnPc}$ were not explored beyond $900 \mathrm{~cm}^{-1}$ from the band origin of the Q state for experimental reasons. As shown in Fig. 6, the spectra for $\mathrm{H}_{2} \mathrm{Pc}$ are the same in all matrices up to $\sim 900 \mathrm{~cm}^{-1}$, but differences appear at higher wavenumbers. The reason for this is the fact that the $\mathrm{Q}_{\mathrm{Y}}$ state of $\mathrm{H}_{2} \mathrm{Pc}$, located around $1000 \mathrm{~cm}^{-1}$ from $\nu_{0-0}$ of $\mathrm{Q}_{\mathrm{X}}$, can induce a coupling with excited vibrational levels of the $\mathrm{Q}_{\mathrm{X}}$ state - the electronic analogue of the Fermi resonance. Since the $\mathrm{Q}_{\mathrm{X}}-\mathrm{Q}_{\mathrm{Y}}$ splitting depends on the matrix, as quoted in Table 1, the vibronic resonance will couple different excited state vibrational modes with the $\mathrm{Q}_{\mathrm{Y}}$ state in different matrices. For the same reason, the coupling may be quite different for the different sites present in a single matrix.

\section{Discussion}

\section{A. Vibronic structure in emission}

$\mathrm{ZnPc}$ and $\mathrm{H}_{2} \mathrm{Pc}$ are large molecules exhibiting very many vibrational modes (165 and 168 respectively) but due to their high symmetry ( $D_{4 h}$ and $D_{2 h}$ respectively) these modes can be 

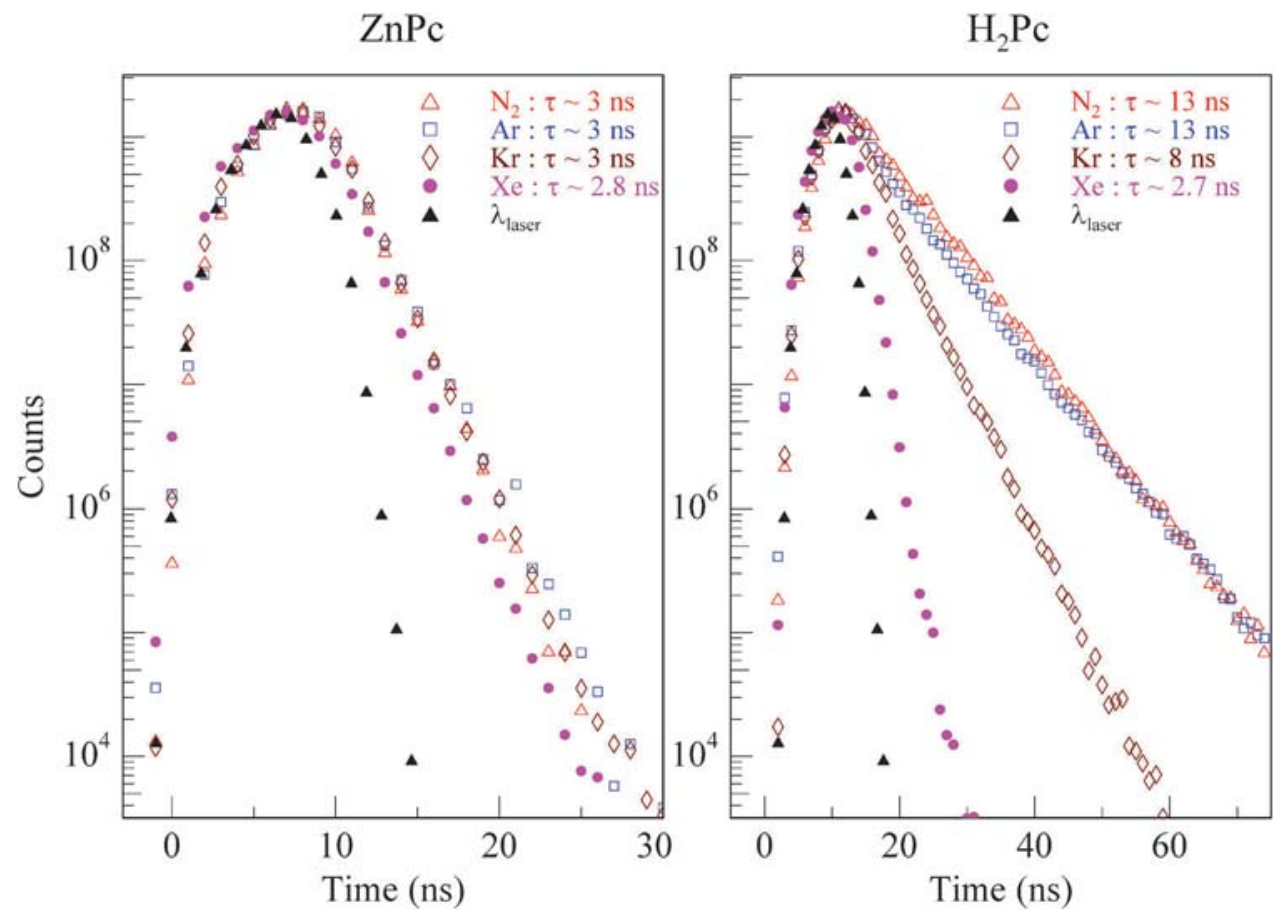

Fig. 4 Semilog plots of the emission decay curves extracted from time resolved emission spectra recorded at $13 \mathrm{~K}$ for $\mathrm{ZnPc}_{\mathrm{n}}$ and $\mathrm{H}_{2} \mathrm{Pc}$ isolated in a variety of low temperature matrices. The shape of the excitation pulse of the laser is also shown.

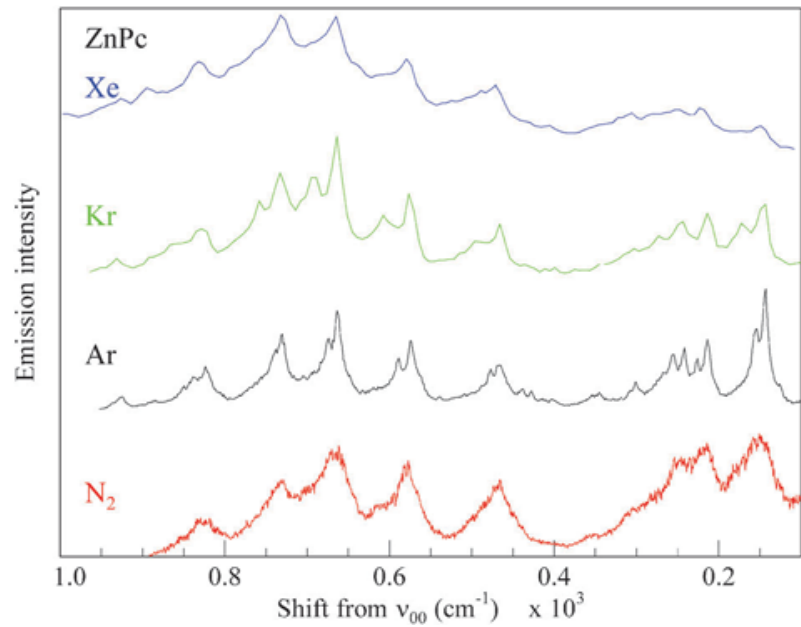

Fig. 5 A comparison of the fluorescence excitation spectra of $\mathrm{ZnPc}$ isolated in $\mathrm{N}_{2}, \mathrm{Ar}, \mathrm{Kr}$ and Xe recorded at $T=13 \mathrm{~K}$ by monitoring the emission corresponding to the vibrational level $1525 \mathrm{~cm}^{-1}$ from the band origin. All the data shown is presented as a shift from the band origin. The band structure reveals evidence for two distinct sites for $\mathrm{ZnPc}$ especially in Ar and Kr. The asymmetric shape on the blue side of most bands arises from phonon effects.

classified into a limited number of symmetry groups. A simplifying consequence of the high symmetry is that the number of modes which are infrared or Raman active is greatly reduced. Furthermore, as these molecules have a centre of inversion, there is mutual exclusion between the IR-active and Raman-active modes, as indicated by the vibrational representations. Selection rules will also reduce the number of vibrational modes involved in the electronic transitions.

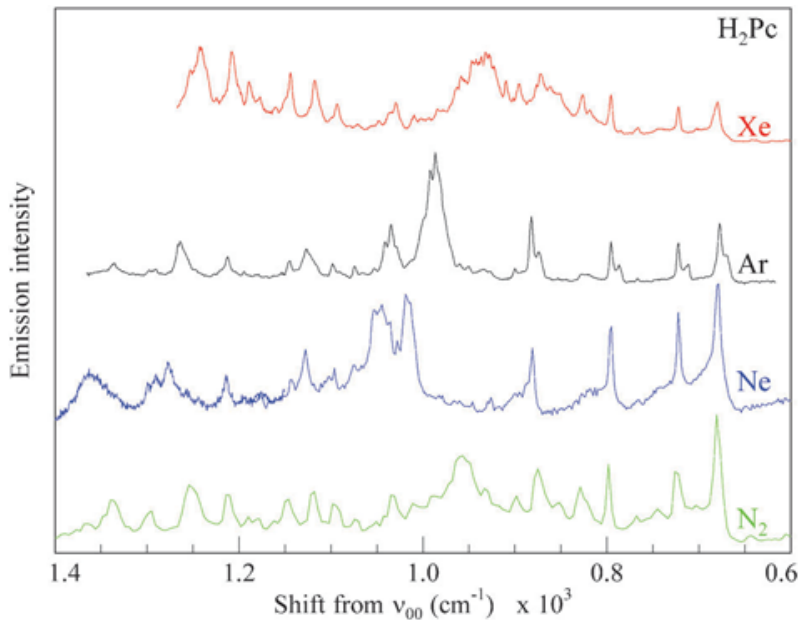

Fig. 6 A comparison of the fluorescence excitation spectra of $\mathrm{H}_{2} \mathrm{Pc}$ isolated in $\mathrm{Ne}, \mathrm{Ar}$ and $\mathrm{Xe}$ at $T=8 \mathrm{~K}$ recorded by monitoring the emission corresponding to the vibrational level $1550 \mathrm{~cm}^{-1}$ from the band origin. The $\mathrm{N}_{2}$ data was obtained from the origin of the $\mathrm{Q}_{\mathrm{x}}$ state. Particularly noteworthy in this plot is the similarity of the vibronic structure up to about $950 \mathrm{~cm}^{-1}$ from the band origin and the irregular nature of the structure present at higher energies. The doublet structure observed most clearly in $\mathrm{Ar}$ is due to the existence of a secondary site. The excitation spectrum shown for $\mathrm{N}_{2}$ corresponds to the most blue site $\left(14859 \mathrm{~cm}^{-1}\right)$ in absorption. Excitation spectra of three other sites are presented in Fig. 9.

The electronic $\mathrm{S}_{1} \leftrightarrow \mathrm{S}_{0}$ transitions for both $\mathrm{ZnPc}$ and $\mathrm{H}_{2} \mathrm{Pc}$ are fully allowed and in the Born-Oppenheimer approximation, only the totally symmetric $\left(\mathrm{a}_{1 \mathrm{~g}}\right.$ and $\mathrm{a}_{\mathrm{g}}$ respectively) vibrational modes of these molecules should be observable in excitation or emission. Nevertheless, an efficient vibronic 
Table 4 Wavenumbers of the observed bands in the excitation spectra of $\mathrm{ZnPc}$ trapped in $\mathrm{N}_{2}, \mathrm{Ar}, \mathrm{Kr}$ and $\mathrm{Xe}$ matrices. The values quoted are the shift from the band origins indicating the vibrational levels in the excited state. The gas phase values were published by Plows and Jones [ref. 6] while the Shpol'skii data is from Huang et al. [ref. 13]. The indicated symmetries were obtained from a comparison with those known from DFT results [ref. 24] in the ground state

\begin{tabular}{llrrrll}
\hline symmetry DFT $(\mathrm{G})$ & Gas phase & $\mathrm{N}_{2}$ & $\mathrm{Ar}$ & $\mathrm{Kr}$ & $\mathrm{Xe}$ & Shpol'skii \\
\hline $\mathrm{B}_{2 \mathrm{~g}}$ & 103 & & 87 & & & \\
$\mathrm{~B}_{1 \mathrm{~g}}$ & 153 & 164 & 154 & 155 & 155 & \\
$\mathrm{~B}_{2 \mathrm{~g}}$ & 226 & 229 & 225 & 224 & 227 & \\
$\mathrm{~A}_{1 \mathrm{~g}}$ & 256 & 259 & 252 & 253 & 255 & \\
$\mathrm{E}_{\mathrm{g}}$ & 306 & & 314 & 315 & 314 & \\
$\mathrm{E}_{\mathrm{g}} ?$ & 324 & & 356 & & & \\
$\mathrm{E}_{\mathrm{g}}$ & 419 & & 412 & 410 & 410 & \\
$\mathrm{E}_{\mathrm{g}} ?$ & 430 & & 439 & & & \\
$\mathrm{~B}_{2 \mathrm{~g}}$ & 482 & 479 & 478 & 476 & 479 & $477 \mathrm{vs}$ \\
$\mathrm{B}_{1 \mathrm{~g}}$ & 565 & & & & & $568 \mathrm{w}$ \\
$\mathrm{A}_{1 \mathrm{~g}}$ & 589 & 593 & 586 & 587 & 586 & $587 \mathrm{vs}$ \\
$\mathrm{A}_{1 \mathrm{~g}}$ & & 676 & 675 & 675 & 671 & $673 \mathrm{vs}$ \\
$\mathrm{B}_{1 \mathrm{~g}}$ & & 744 & 742 & 742 & 737 & $742 \mathrm{~s}$ \\
$\mathrm{~A}_{1 \mathrm{~g}}$ & & 832 & 837 & 838 & 837 & $832 \mathrm{~m} / 839 \mathrm{~m}$ \\
$\mathrm{E}_{\mathrm{g}} ?$ & & 846 & 851 & & & $851 \mathrm{w}$ \\
$\mathrm{B}_{2 \mathrm{~g}}$ & & & 940 & 942 & & $937 \mathrm{w}$ \\
\hline
\end{tabular}

mixing ${ }^{13}$ occurs between the $S_{1}$ state and the Soret states so that modes of other symmetries will appear in the spectra. For $\mathrm{ZnPc}$ whose $\mathrm{Q}\left(\mathrm{S}_{1}\right)$ state has ${ }^{1} \mathrm{E}_{\mathrm{u}}$ symmetry, modes that transform as the $a_{1 g}, a_{2 g}, b_{1 g}$ and $b_{2 g}$ irreducible representations can induce this coupling. Similarly, the $\mathrm{Q}_{\mathrm{X}}\left(\mathrm{S}_{1}\right)$ state of $\mathrm{H}_{2} \mathrm{Pc}$, which has ${ }^{1} \mathrm{~B}_{3 \mathrm{u}}$ symmetry, will be coupled to the Soret states by $a_{g}$ and $b_{1 g}$ modes. All these modes, except the $a_{2 g}$ modes of $\mathrm{ZnPc}$, are Raman active modes. Additional modes which are Raman active are $\mathrm{e}_{\mathrm{g}}$ modes in the $D_{4 h}$ group of symmetry and $b_{2 g}$ and $b_{3 g}$ modes in the $D_{2 h}$ group of symmetry. These modes correspond to out-of-plane vibrations in the cases of $\mathrm{ZnPc}$ and $\mathrm{H}_{2} \mathrm{Pc}$. In agreement with the experimental Raman results, our recent vibrational analysis of $\mathrm{ZnPc}$ and $\mathrm{H}_{2} \mathrm{Pc}^{24}$ found the intensities of the out-of-plane Raman-active modes to be very weak. So from symmetry considerations, strong similarities are expected between Raman and emission spectra.

The normal Raman spectra of $\mathrm{ZnPc}$ and $\mathrm{H}_{2} \mathrm{Pc}$ recorded in $\mathrm{KBr}$ pellets with continuous-wave $532 \mathrm{~nm}$ excitation are shown in Fig. 3 by the red traces along with the emission recorded in Ar matrices (black traces). The vibrational frequencies measured for the Raman active modes of both

Table 5 Wavenumbers of the observed bands in the excitation spectra of $\mathrm{H}_{2} \mathrm{Pc}$ trapped in $\mathrm{Ne}, \mathrm{N}_{2}, \mathrm{Ar}, \mathrm{Kr}$ and Xe matrices. The values quoted are the shift from the band origins indicating the vibrational levels in the excited state. The gas phase values were published by Plows and Jones [ref. 6] with additional values (shown in italics) from Fitch et al. [ref. 7] while the Shpol'skii data is from Huang et al. [ref. 13]. The indicated symmetries were obtained from a comparison with those known from DFT results [ref. 24] in the ground state

\begin{tabular}{|c|c|c|c|c|c|c|c|}
\hline Symmetry (G) & Gas phase & $\mathrm{Ne}$ & $\mathrm{N}_{2}$ & $\mathrm{Ar}$ & $\mathrm{Kr}$ & $\mathrm{Xe}$ & Shpol'skii \\
\hline$B_{1 g}$ & & & & 87 & & 86 & \\
\hline $\mathrm{A}_{\mathrm{g}}$ & 127 & & 131 & 129 & & 129 & 136 \\
\hline $\mathrm{B}_{1 \mathrm{~g}}$ & & & 179 & 175 & & 172 & - \\
\hline $\mathrm{A}_{\mathrm{g}}$ & 226 & & 229 & 228 & & & 231 \\
\hline $\mathrm{B}_{1 \mathrm{~g}}^{\mathrm{z}}$ & 476 & 476 & - & & & & 474 \\
\hline$A_{g}$ & 566 & 568 & - & & & & 565 \\
\hline$A_{g}^{s}$ & 678 & 680 & - & 677 & & 680 & 679 \\
\hline$A_{g}$ & 723 & 720 & 719 & 722 & & 722 & 720 \\
\hline$A_{g}$ & & 763 & 763 & 768 (vw) & & $766(\mathrm{vw})$ & 779 \\
\hline \multirow[t]{2}{*}{$A_{g}$} & 794 & 793 & 794 & 795 & 795 & 795 & 799 \\
\hline & & & - & & 811 & 819 & $809 / 818$ \\
\hline $\mathrm{B}_{1 \mathrm{~g}}$ & & 822 & 824 & $828(\mathrm{vw})$ & $825(\mathrm{vw})$ & 827 & 828 \\
\hline \multirow[t]{7}{*}{$\mathrm{B}_{1 \mathrm{~g}}$} & 887 & 880 & $877^{a}$ & 882 & 876(large) & $861-872$ & 890 \\
\hline & & & $895^{a}$ & 900 & & 895 & 900 \\
\hline & & & 906 & & & 910 & \\
\hline & & $926(\mathrm{vw})$ & 931 & 933 (vw) & & $928-932$ & 933 \\
\hline & & & 947 & 949 (vw) & 946 & 946 & \\
\hline & & & 957 & $960(\mathrm{vw})$ & 956 & 958 & - \\
\hline & 978 & 979 & $1000-970^{b}$ & 987-991 & & 983 & 982 \\
\hline \multirow[t]{2}{*}{$A_{g}$} & & 1010 & 1010 & 1009 (vw) & 1013 & 1016 & 1009 \\
\hline & & 1017 & & & & & \\
\hline \multirow[t]{4}{*}{$\mathrm{B}_{1 \mathrm{~g}}$} & 1025 & 1024 & $1028^{a}$ & 1034 & & & $1024 / 1027$ \\
\hline & 1030 & 1034 & $1037^{a}$ & 1041 & 1033 & 1030 & 1036 \\
\hline & 1044 & 1043 & 1048 & 1052 & 1044 & 1048 & \\
\hline & 1059 & 1051 & & & 1064 & & - \\
\hline $\mathrm{B}_{1 \mathrm{~g}}$ & 1078 & 1074 & $1069^{a}$ & 1074 & 1081 & 1070 & 1083 \\
\hline $\mathrm{B}_{1 \mathrm{~g}}$ & 1086 & 1096 & 1092 & 1098 & 1111 & 1094 & 1109 \\
\hline $\mathrm{A}_{\mathrm{g}}$ & & 1128 & 1119 & 1126 & 1128 & 1118 & 1115 \\
\hline$A_{g}$ & 1137 & 1142 & 1142 & 1144 & 1150 & 1143 & 1142 \\
\hline$A_{g}$ & & 1178(vw) & 1178 & & 1176 & $1161(\mathrm{vw})$ & 1156 \\
\hline$A_{g}$ & 1184 & & 1189 & $1194(\mathrm{vw})$ & & 1189 & 1180 \\
\hline \multirow[t]{2}{*}{$\mathrm{B}_{1 \mathrm{~g}}$} & 1221 & 1214 & 1214 & 1212 & 1213 & 1208 & 1205 \\
\hline & & & 1254 & 1264 & 1251 & 1243 & 1239 \\
\hline $\mathrm{A}_{\mathrm{g}}$ & 1285 & 1278 & 1295 & $1291-1297$ & 1285 & & 1288 \\
\hline$A_{g}^{g}$ & 1334 & 1350 & 1339 & 1336 & 1353 & & 1355 \\
\hline
\end{tabular}

${ }^{a}$ Frequencies depending on the site: they decrease with increasing frequency of the site. ${ }^{b}$ Main band with frequency depending on the site: its frequency decreases with increasing frequency of the site- see text and Fig. 9. 
molecules have been presented and analysed by us. ${ }^{24}$ What is most evident in Fig. 3 is the very strong similarity between the visible emission and the normal Raman spectra in the case of both molecules. Thus while there are some intensity differences between the emission and Raman spectra, the line positions all agree. The significance of this observation is that the mode assignments established by us $^{24}$ for the Raman bands can now be used to assign the bands present in the emission spectra.

The theoretically predicted Raman spectra of $\mathrm{H}_{2} \mathrm{Pc}$ and $\mathrm{ZnPc}$ are compared with experimental Raman and fluorescence data in Fig. S1 and S2 respectively of the supplementary material provided. Assignment of the vibronic structure of the emission spectra is then possible using the ground state Raman results. The most prominent bands in the emission and Raman spectra are numbered in these figures and the mode assignments, taken from the DFT Raman predictions, are listed in Table 6 for $\mathrm{ZnPc}$ and $\mathrm{H}_{2} \mathrm{Pc}$, highlighting the similarities between both molecules. The most intense Raman active mode for $\mathrm{ZnPc}$ is predicted at $1526 \mathrm{~cm}^{-1}$ with $\mathrm{b}_{\mathrm{g}}$ symmetry, corresponding to an out-of-phase stretching of the $\mathrm{C}-\mathrm{N}-\mathrm{C}$ bonds in the tetrapyrrole ring. The corresponding mode is predicted at $1551 \mathrm{~cm}^{-1}$ for $\mathrm{H}_{2} \mathrm{Pc}$. It is noteworthy that the fluorescence bands at $1525 \mathrm{~cm}^{-1}$ for $\mathrm{ZnPc}$ and at $1550 \mathrm{~cm}^{-1}$ for $\mathrm{H}_{2} \mathrm{Pc}$, which exhibit ${ }^{27}$ efficient stimulated emission (SE), are very close to the calculated frequency for the most intense Raman mode of both molecules. In more concentrated samples or under higher laser excitation intensity, two other modes have been observed to exhibit SE. This effect is especially prevalent in $\mathrm{H}_{2} \mathrm{Pc} / \mathrm{N}_{2}$ samples where the modes at $730 \mathrm{~cm}^{-1}$ and $688 \mathrm{~cm}^{-1}$ also produce stimulated emission. These two modes are also quite intense in fluorescence and Raman spectra and both correspond to concerted motion of the inner-ring of the molecule. On the other hand, stimulated emission was also observed in free-base tetra-benzo porphine $\left(\mathrm{H}_{2} \mathrm{TBP}\right)$ in $\mathrm{Ar}$ and $\mathrm{H}_{2} \mathrm{TBP} / \mathrm{N}_{2}$ samples on a $\mathrm{S}_{1}-\mathrm{S}_{0}$ vibronic transition towards a vibrational excitation of $\mathrm{H}_{2} \mathrm{TBP}$ in the ground state corresponding to an out-of-phase stretching of the $\mathrm{C}-\mathrm{C}-\mathrm{C}$ bonds in the internal ring, the analogue ${ }^{28}$ of the $1550 \mathrm{~cm}^{-1}$ excitation of $\mathrm{H}_{2} \mathrm{Pc}$. This analysis provides the first information on the characteristics of the vibrations involved in SE.

The good agreement between the Raman and fluorescence frequencies was expected because of the similar selection rules, but the observed intensities in Raman and fluorescence spectra are also quite similar. This is consistent with the fact that all the vibronic transitions observed in fluorescence are transitions from $\mathrm{v}_{\mathrm{i}}{ }^{\prime}=0$ to $\mathrm{v}_{\mathrm{f}}{ }^{\prime \prime}=1$ for different vibrational modes, i.e. no overtones or progressions are present in the observed emission spectra.

\section{B. ZnPc excitation spectra}

Fig. 7 provides a comparison of the excitation and emission spectra recorded for zinc phthalocyanine in Ar. In this figure the emission spectrum has been reversed around the band origin of the $\mathrm{Q}\left(\mathrm{S}_{1}\right) \rightarrow \mathrm{G}\left(\mathrm{S}_{0}\right)$ transition for the purpose of comparison with the excitation and/or absorption spectra. The characteristic most evident in Fig. 7 is the mirror symmetry that exists between the excitation (red trace) and emission (blue trace) spectra as very well illustrated by the Ar data shown. The apparent weak intensity of the $0-0$ band in excitation is an artefact due to strong re-absorption arising from the overlap between absorption and emission bands. The frequencies found for the vibronic modes in emission and excitation in a variety of matrices can be compared in Tables 2 and 4 respectively.

The same selection rules exist for the vibronic coupling of an electronic transition in both absorption and emission and since both transitions originate from the vibrationless levels, similar spectra arise. The observed similarities in the vibronic intensity

Table 6 Descriptions of the vibrational motion for the 17 most intense bands in the emission spectra of $\mathrm{ZnPc}$ and $\mathrm{H}_{2} \mathrm{Pc}$ in $\mathrm{Ar}$. The emission values are compared with the observed Raman data previously published by us [ref. 24]. The symmetry labels are from the same work and were obtained from large basis-set DFT calculations. The frequencies are given in wavenumber $\left(\mathrm{cm}^{-1}\right)$ units and all the observed Raman modes involve in-plane motions. The spectral precision in emission is around $4-5 \mathrm{~cm}^{-1}$ and is slightly better than this in Raman $\left(1-2 \mathrm{~cm}^{-1}\right)$, however, the latter data were recorded at room temperature from in $\mathrm{KBr}$ pellets while the emission is Ar matrix data recorded at $10 \mathrm{~K}$. The discrepancy is larger for $\mathrm{ZnPc}$ than for $\mathrm{H}_{2} \mathrm{Pc}$, because of the broadening of the emission bands

\begin{tabular}{|c|c|c|c|c|c|}
\hline Band \# & $\begin{array}{l}\text { ZnPc } \\
\text { Obs. } \\
\text { Emiss. }\end{array}$ & $\begin{array}{l}\text { Raman } \\
\text { Observed }\end{array}$ & $\begin{array}{l}\mathrm{H}_{2} \mathrm{Pc} \\
\text { Obs. } \\
\text { Emiss. }\end{array}$ & $\begin{array}{l}\text { Raman } \\
\text { Observed }\end{array}$ & Mode description \\
\hline 1 & 161 & $157\left(\mathrm{~B}_{1 \mathrm{~g}}\right)$ & 140 & $130\left(\mathrm{~A}_{\mathrm{g}}\right)$ & Bridging $\mathrm{C}-\mathrm{N}-\mathrm{C}$ sym. deformation \\
\hline 2 & 237 & $228\left(\mathrm{~B}_{2 \mathrm{~g}}\right)$ & 190 & $183\left(\mathrm{~B}_{1 \mathrm{~g}}\right)$ & Bridging $\mathrm{C}-\mathrm{N}-\mathrm{C}$ asym. deformation \\
\hline 3 & 260 & $257\left(\mathrm{~A}_{1 \mathrm{~g}}\right)$ & 238 & $228\left(\mathrm{~A}_{\mathrm{g}}\right)$ & Central ring breathing \\
\hline 4 & 490 & $480\left(\mathrm{~B}_{2 \mathrm{~g}}\right)$ & 489 & $480\left(\mathrm{~B}_{1 \mathrm{~g}}\right)$ & Aryl rocking \& central ring def. \\
\hline 5 & 598 & $588\left(\mathrm{~A}_{1 \mathrm{~g}}\right)$ & 576 & $566\left(\mathrm{~A}_{\mathrm{g}}\right)$ & Aryl deformation/central ring breathing \\
\hline 6 & 689 & $677\left(\mathrm{~A}_{1 \mathrm{~g}}\right)$ & 688 & $680\left(\mathrm{~A}_{\mathrm{g}}\right)$ & Bridging $\mathrm{C}-\mathrm{N}-\mathrm{C}$ sym. def and aryl def \\
\hline 7 & 751 & $747\left(\mathrm{~B}_{1 \mathrm{~g}}\right)$ & 730 & $723\left(\mathrm{~A}_{\mathrm{g}}\right)$ & Pyrrole deformation and $\mathrm{C}-\mathrm{N}-\mathrm{C}$ rocking \\
\hline 8 & 845 & $830\left(\mathrm{~A}_{1 \mathrm{~g}}\right)$ & 802 & $796\left(\mathrm{~A}_{\mathrm{g}}\right)$ & Pyrrole \& aryl $\mathrm{C}-\mathrm{C}$ str. \\
\hline 9 & 945 & $946\left(\mathrm{~B}_{2 \mathrm{~g}}\right)$ & 1090 & $1081\left(B_{1 \mathrm{~g}}\right)$ & $\mathrm{ZnPc}$ asym $\mathrm{CNC}$ bend $/ \mathrm{H}_{2} \mathrm{Pc} \mathrm{N}-\mathrm{H}$ IPB \\
\hline 10 & 1004 & $1009\left(\mathrm{~A}_{1 \mathrm{~g}}\right)$ & 1006 & $1007\left(\mathrm{~A}_{\mathrm{g}}\right)$ & Sym.aryl C-H def \\
\hline 11 & 1150 & $1142\left(\mathrm{~B}_{1 \mathrm{~g}}\right)$ & 1145 & $1140\left(\mathrm{~A}_{\mathrm{g}}\right)$ & Aryl $\mathrm{C}-\mathrm{C}$ str. and $\mathrm{C}-\mathrm{H}$ def \\
\hline 12 & 1183 & $1183\left(\mathrm{~B}_{1 \mathrm{~g}}\right)$ & 1188 & $1181\left(\mathrm{~A}_{\mathrm{g}}\right)$ & $\mathrm{C}-\mathrm{H}$ def on aryl ring \\
\hline 13 & 1221 & $1210\left(\mathrm{~B}_{2 \mathrm{~g}}\right)$ & 1228 & $1228\left(\mathrm{~B}_{1 \mathrm{~g}}\right)$ & $\mathrm{C}-\mathrm{H}$ def/ aryl def and N-H IPB \\
\hline 14 & 1346 & $1338\left(\mathrm{~A}_{1 \mathrm{~g}}\right)$ & 1350 & $1337\left(\mathrm{~A}_{\mathrm{g}}\right)$ & Aryl $\mathrm{C}-\mathrm{C}$ str. and pyrrole $\mathrm{C}-\mathrm{C}$ stretch \\
\hline 15 & 1448 & $1447\left(B_{1 \mathrm{~g}}\right)$ & 1456 & $1451\left(\mathrm{~A}_{\mathrm{g}}\right)$ & $\mathrm{C}-\mathrm{H}$ def \\
\hline 16 & 1525 & $1507\left(\mathrm{~B}_{1 \mathrm{~g}}\right)$ & 1550 & $1540\left(\mathrm{~A}_{\mathrm{g}}\right)$ & $\begin{array}{l}\text { Bridging } \mathrm{C}_{\alpha}-\mathrm{N}_{\mathrm{m}}-\mathrm{C}_{\alpha} \text { asym.str and sym str } \\
\text { of the } \mathrm{C}_{\alpha}-\mathrm{N}_{\mathrm{H}}-\mathrm{C}_{\alpha} \text { bonds }\end{array}$ \\
\hline 17 & 1624 & $1608\left(\mathrm{~B}_{2 \mathrm{~g}}\right)$ & 1605 & $1616\left(B_{1 \mathrm{~g}}\right)$ & Aryl ring deformation \\
\hline
\end{tabular}




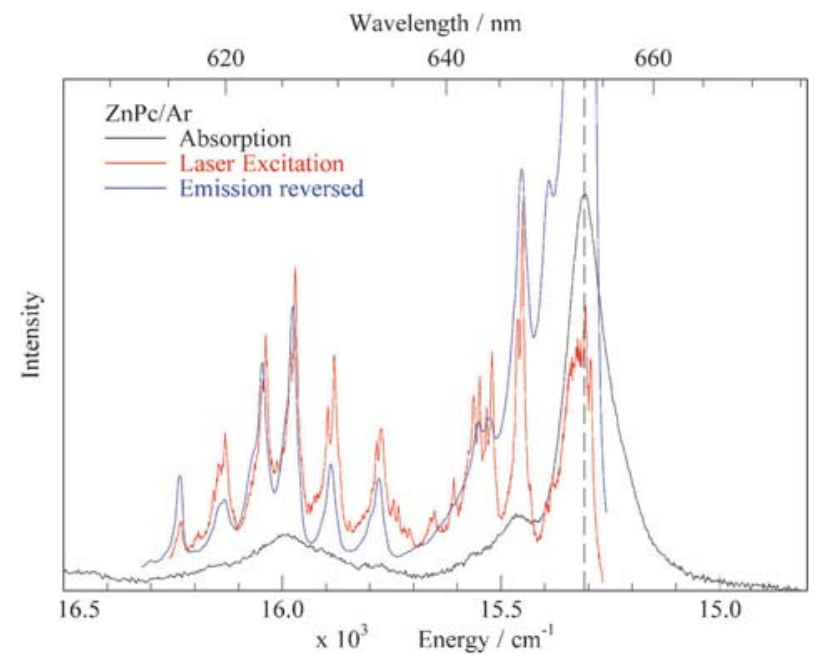

Fig. 7 A comparison of the absorption (black trace), excitation spectra and reversed emission spectra of $\mathrm{ZnPc} / \mathrm{Ar}$. Very good agreement exists between the excitation and reversed emission indicating immediately the strong mirror symmetry which exists between the two spectra. The dashed vertical line indicates the position of the band origin of the $0-0$ transition at $15309 \mathrm{~cm}^{-1}$ in the Ar matrix.

distributions in emission and excitation indicate that the geometry in this molecule is not greatly changed when in the first excited electronic state compared to the ground state. This is also confirmed by the fact that the $0-0$ band is the most intense band in fluorescence spectra. Another key observation which can be made is that positions of the $0-0$ transition in emission and excitation in all matrices agree to within the experimental error of our spectroscopic setups. Thus there is no Stokes shift on the Q state emission indicating very similar solvated geometries in the ground and first excited electronic states.

The vibrational frequencies of the two electronic states $\mathrm{G}\left(\mathrm{S}_{0}\right)$ and $\mathrm{Q}\left(\mathrm{S}_{1}\right)$ of $\mathrm{ZnPc}$ isolated in different matrices are in good agreement with the values obtained in Shpol'skii matrices ${ }^{13}$ and those obtained in the gas phase ${ }^{6}$ as shown in Tables 2 and 4 respectively. The discrepancy from mirror symmetry between excitation and emission noticed in Shpol'skii matrices ${ }^{13}$ concerned the vibronic structure at higher energy. The absorption spectra recorded in the present study indicate this behaviour is not observed in matrices.

In the gas phase, 13 vibronic bands have been observed ${ }^{6}$ in excitation for $\mathrm{ZnPc}$ ranging from 33 to $589 \mathrm{~cm}^{-1}$ from the band origin. As collected in Table 4 and shown in Fig. 5, all these modes have been observed for $\mathrm{ZnPc}$ in matrices at very similar energies except for the modes at 33,103, 131 and $565 \mathrm{~cm}^{-1}$. The last value corresponds to a weakly observed band in Shpol'skii matrices, ${ }^{13}$ but the other values, corresponding to very weak bands, are not observed in any host, including helium droplets. ${ }^{10}$ In matrices, the low frequency modes could be hidden in the phonon side band of the $0-0$ band. The first clearly observed vibrational excitation is around $155 \mathrm{~cm}^{-1}$. In jet-cooled experiments ${ }^{6}$ the most intense band by far was the $0-0$ transition, with this band at $153 \mathrm{~cm}^{-1}$ the second most intense in the spectrum. This is also what Lehnig et al. ${ }^{10}$ observed in helium droplets. On the other hand, there are some discrepancies in the symmetry assignment of the vibrational bands between Plows' paper ${ }^{6}$ and our results reported in Table 4 based on DFT calculations and a detailed comparison between the vibrational modes of $\mathrm{ZnPc}$ and $\mathrm{H}_{2} \mathrm{Pc}^{24}$ Similar discrepancies occur between ref. 6 and Table 5 in the assignments of the vibrational levels of $\mathrm{H}_{2} \mathrm{Pc}$.

\section{C. $\mathbf{H}_{2}$ Pc excitation spectra}

1. General remarks. In contrast to $\mathrm{ZnPc}$, a breakdown of the mirror symmetry occurs in excitation and emission spectra of $\mathrm{H}_{2} \mathrm{Pc}$ around $1000 \mathrm{~cm}^{-1}$ above the band origin, $\nu_{0-0}$, (Table 3 and 5 respectively) as illustrated in Fig. 8 for the case of $\mathrm{H}_{2} \mathrm{Pc}$ in Ar. As revealed in Fig. 8, there is very good agreement between excitation and emission up to $800 \mathrm{~cm}^{-1}$ (energy around $15600 \mathrm{~cm}^{-1}$ ) above the origin of the $\mathrm{Q}_{\mathrm{X}}$ state. Beyond this value, there is a pronounced lack of mirror symmetry where a gap exists in the emission frequencies, while broad strong bands appear in this range in excitation. This difference in vibronic structure between emission and excitation arises because of the existence of the $\mathrm{Q}_{\mathrm{Y}}\left(\mathrm{S}_{2}\right)$ state at $\sim 1000 \mathrm{~cm}^{-1}$ from the $\mathrm{Q}_{\mathrm{X}}\left(\mathrm{S}_{1}\right)$ state, which is not present in $\mathrm{ZnPc}$. It is expected that excited vibrational levels of the $\mathrm{Q}_{\mathrm{x}}$ state will be situated in the same region as the band origin of the electronic $Q_{Y} \leftarrow G$ transition. When coupling occurs between the two electronic states, the vibronic lines of the $\mathrm{Q}_{\mathrm{x}} \leftarrow \mathrm{G}$ transition increase in intensity and are shifted-the vibronic analogue of Fermi resonance. ${ }^{33}$ The oscillator strength of the $\mathrm{Q}_{\mathrm{Y}} \leftarrow \mathrm{G}$ transition is then distributed among a number of vibronic $Q_{x} \leftarrow G$ transitions rendering the exact position of the band origin of $\mathrm{Q}_{\mathrm{Y}}$ difficult to determine.

When the manifold of the $Q_{X}$ state vibronic levels in resonance with the origin of $\mathrm{Q}_{\mathrm{Y}}$ is not dense, and the vibrational structure is well resolved, the band origin of the latter

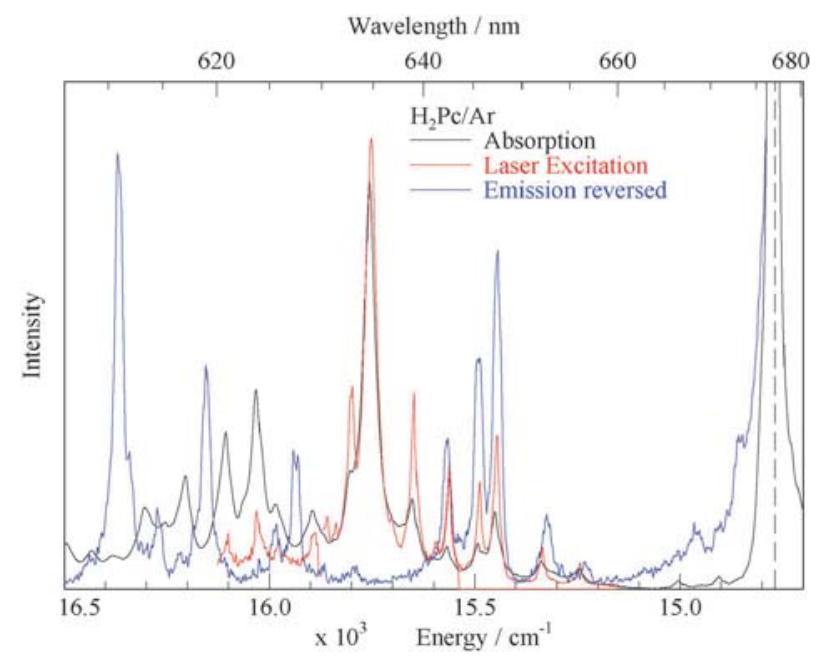

Fig. 8 Same comparison as presented in Fig. 7 but for $\mathrm{H}_{2} \mathrm{Pc} / \mathrm{Ar}$ data. It is evident in this plot that the vibronic structure up to about $950 \mathrm{~cm}^{-1}$ from the band origin are similar in emission and excitation but that the latter becomes irregular at higher energies. Particularly noteworthy are the intense bands which are present in the excitation in the region of $1000 \mathrm{~cm}^{-1}$ but which are absent in emission. The dashed vertical line indicates the position of the $0-0$ transition at $14768 \mathrm{~cm}^{-1}$ in solid Ar. 
can be distinguished in the spectra. This condition existed in the low temperature spectra recorded by Arabei et al. ${ }^{34}$ in the case of $\mathrm{H}_{2}$ TBP in $n$-alkane crystals. In contrast when this manifold is very dense, direct line-to-line assignment is not possible and the energy of the $\mathrm{Q}_{\mathrm{Y}}$ state is estimated from a band analysis ${ }^{33,35}$ involving deconvolution of conglomerates of bands. In the case of $\mathrm{H}_{2} \mathrm{Pc}$, the energies of modes with the right $\left(b_{1 \mathrm{~g}}\right)$ symmetry for efficient coupling between the $\mathrm{Q}_{\mathrm{X}}$ and $\mathrm{Q}_{\mathrm{Y}}$ states are now known from recent DFT results ${ }^{24}$ and are shown in Fig. 10 for fundamentals and combination of pairs. As indicated in the figure, the $\mathrm{Q}_{\mathrm{X}}-\mathrm{Q}_{\mathrm{Y}}$ energy gap is in an energy range where very few fundamental $b_{1 \mathrm{~g}}$ modes exist.

2. Matrix and site effects on the $Q_{X} / Q_{Y}$ state couplings. The $\mathrm{QX}_{\mathrm{X}}-\mathrm{Q}_{\mathrm{Y}}$ splitting of $\mathrm{H}_{2} \mathrm{Pc}$ is matrix dependent as is evident in the absorption and excitation spectra presented in Fig. 2 and 6 respectively (see Table 1 for values). As a result, different vibronic bands of $\mathrm{Q}_{\mathrm{X}}$ will couple with the band origin of the

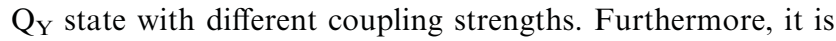
also to be expected that distinct sites in the same matrix may exhibit different $\mathrm{Q}_{\mathrm{X}}-\mathrm{Q}_{\mathrm{Y}}$ splittings. This phenomenon has already been observed for other porphyrins (meso-tetraazaporphine, meso-tetrapropyl-porphine and tetrabenzoporphine) in Shpol'skii matrices. ${ }^{33,35}$ In the case of $\mathrm{H}_{2} \mathrm{Pc}$, this effect can be followed very well in nitrogen matrices which present many different sites of isolation as illustrated in the panels on the right of Fig. 9.

Table 1 reveals the decrease in energy of the $\mathrm{Q}_{\mathrm{x}}$ origin from the gas phase to xenon matrices through $\mathrm{He}$ droplets, $\mathrm{Ne}, \mathrm{N}_{2}$, $\mathrm{Ar}$ and $\mathrm{Kr}$ hosts successively. The $\mathrm{Q}_{\mathrm{X}}-\mathrm{Q}_{\mathrm{Y}}$ splitting follows qualitatively the same host dependence, decreasing from the gas phase to Xe matrices. It is known from Huang's results ${ }^{13}$
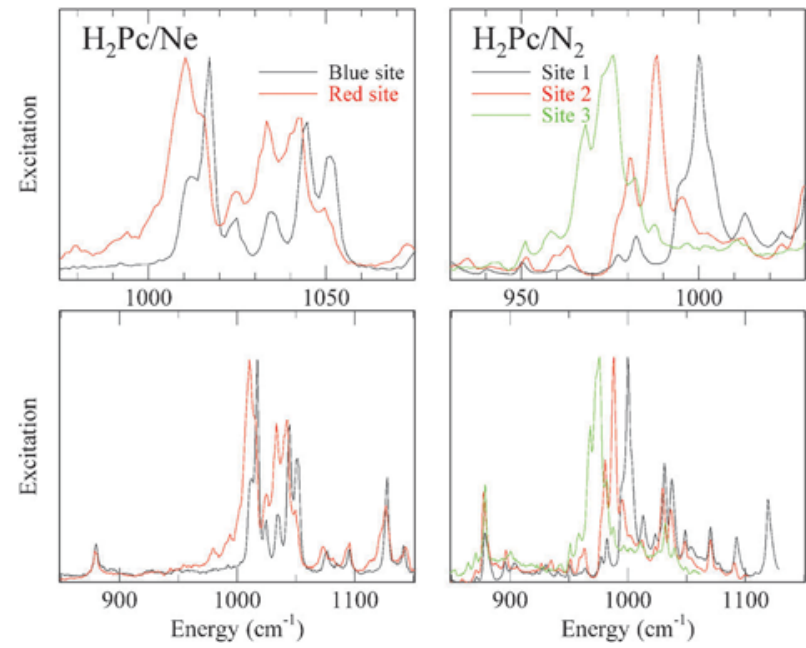

Fig. 9 Detail of the excitation spectra in the region where coupling can occur between the band origin of the $Q_{Y}$ state and excited vibrational levels of $\mathrm{Q}_{\mathrm{X}}$. The data presented was recorded in neon (left panel) and nitrogen (right) by monitoring emission of the band origin of the $\mathrm{Q}_{\mathrm{X}}-\mathrm{G}$ transition. All the spectra are shown relative to the bands origin of the $\mathrm{Q}_{\mathrm{X}}$ state. In Ne the blue and red sites are located at 15007 and $14934 \mathrm{~cm}^{-1}$ respectively while sites 1,2 and 3 in $\mathrm{N}_{2}$ are at 14761, 14787 and $14832 \mathrm{~cm}^{-1}$ respectively. Most evident in this comparison is the relatively simple structure present in $\mathrm{N}_{2}$ and the much more complex bands in $\mathrm{Ne}$. in Shpol'skii matrices that an even smaller G- $\mathrm{Q}_{\mathrm{X}}$ transition energy exists in $n$-decane than in Xe together with a reduced splitting between the $\mathrm{Q}_{\mathrm{X}}$ and $\mathrm{Q}_{\mathrm{Y}}$ states. In gas phase jet experiments, Fitch et al. ${ }^{7}$ identified the origin of the $\mathrm{Q}_{\mathrm{Y}}$ state around $16700 \mathrm{~cm}^{-1}$, due to a large intensity increase of congested bands in this spectral region. More recently, Plows and Jones ${ }^{6}$ reported the onset of the $\mathrm{Q}_{\mathrm{Y}}$ band around $1000 \mathrm{~cm}^{-1}$ above the $\mathrm{Q}_{\mathrm{X}}$ origin. The latter assignment is in good agreement with the results on $\mathrm{H}_{2} \mathrm{Pc}$ in helium droplets. ${ }^{10}$ Moreover, Fitch et al. ${ }^{8}$ observed in their jet experiments a large broadening of fluorescence bands when exciting $\mathrm{H}_{2} \mathrm{Pc}$ at $16188 \mathrm{~cm}^{-1}$, i.e. $1056 \mathrm{~cm}^{-1}$ above the $\mathrm{Q}_{\mathrm{X}}$ origin, which could be correlated to an excitation of a coupled $\mathrm{Q}_{\mathrm{X}}-\mathrm{Q}_{\mathrm{Y}}$ vibronic band. As this band is the most intense in this spectral range, it can be assigned in a first approximation to the origin of the $\mathrm{Q}_{\mathrm{Y}}$ state in the gas phase. From the work of Fitch et al. ${ }^{8}$ and Lehnig et al., ${ }^{10}$ it seems that the $\mathrm{Q}_{\mathrm{X}}-\mathrm{Q}_{\mathrm{Y}}$ splitting is not modified appreciably by the helium droplet environment. The least perturbing matrix host is neon, and effectively, the excitation band pattern in this host (shown in Fig. 9) remains very similar to the case of $\mathrm{He}$ around the $\mathrm{Q}_{\mathrm{Y}}$ origin, involving the same vibronic levels.

According to the DFT results ${ }^{24}$ shown in Fig. 10, only three fundamental $b_{1 \mathrm{~g}}$ modes exist in the $1000-1100 \mathrm{~cm}^{-1}$ spectral range in the ground state. These modes have been observed ${ }^{24}$ in Raman spectra at 1026, 1081 and $1099 \mathrm{~cm}^{-1}$. The same modes appear in the excitation spectra of $\mathrm{H}_{2} \mathrm{Pc}$ in the jet experiments ${ }^{7}$ together with a few other weak bands coming from the interaction of $\mathrm{Q}_{\mathrm{X}}$ modes via interstate coupling with the $\mathrm{Q}_{\mathrm{Y}}$ origin. Whereas all these modes appear also in the excitation spectra of $\mathrm{H}_{2} \mathrm{Pc}$ isolated in $\mathrm{Ne}$, their intensity

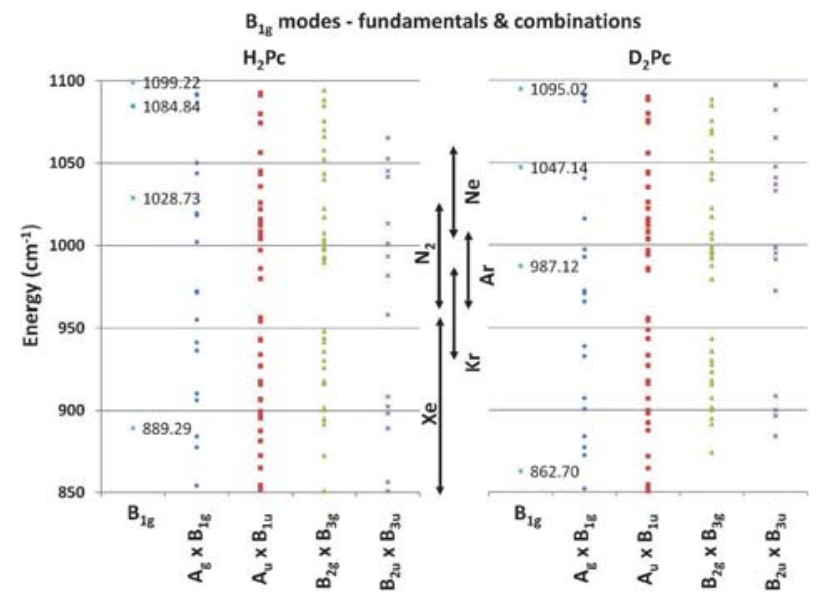

Fig. 10 An energy level diagram showing the vibrational modes of $\mathrm{H}_{2} \mathrm{Pc}$ and $\mathrm{D}_{2} \mathrm{Pc}$ with the correct symmetry $\left(\mathrm{b}_{1 \mathrm{~g}}\right)$ to couple the $\mathrm{QX}_{\mathrm{X}}$ and $Q_{Y}$ electronic states in the region of the band origin of the $Q_{Y}$ state. Fundamental $\mathrm{B}_{1 \mathrm{~g}}$ modes are shown with frequencies in wavenumber units. The combinations modes shown are limited to just pairs of modes. The frequencies of both the fundamental and combination bands were determined in recent (scaled) DFT calculations [ref. 24]. The vertical arrows shown in the central region of the plot are the energy ranges of the $\mathrm{Q}_{\mathrm{Y}}$ state band origin for the sites present in Ar, $\mathrm{Kr}$ and $\mathrm{N}_{2}$ while those shown for $\mathrm{Ne}$ and $\mathrm{Xe}$ are the ranges observed for the complex band structures present in the region of the band origin of the $\mathrm{Q}_{\mathrm{Y}}$ state in these two hosts. 
distribution is different from that in the gas phase or in $\mathrm{He}$ droplets. In $\mathrm{Ne}$, the most intense band is, as shown in the upper left of Fig. 9, between 1001 and $1017 \mathrm{~cm}^{-1}$, depending on the site (see later), with also large intensities in the bands around $1045 \mathrm{~cm}^{-1}$. We conclude that the $\mathrm{Q}_{\mathrm{X}}-\mathrm{Q}_{\mathrm{Y}}$ splitting is reduced by $40 \mathrm{~cm}^{-1}$ in $\mathrm{Ne}$, with a possible interaction between the fundamental $1026 \mathrm{~cm}^{-1}$ (value from Raman spectra) $b_{1 \mathrm{~g}}$ mode and the $\mathrm{Q}_{\mathrm{Y}}$ state origin. This coupling could explain the intensity distribution over a larger number of main bands in neon.

From our ground state DFT study ${ }^{24}$ there are no fundamental $\mathrm{b}_{1 \mathrm{~g}}$ modes between $1026 \mathrm{~cm}^{-1}$ and $889 \mathrm{~cm}^{-1}$. The $\mathrm{Q}_{\mathrm{X}}-\mathrm{Q}_{\mathrm{Y}}$ splitting reaches this range in the heavier inert gas matrices and consistent with this, the excitation spectra in Ar, $\mathrm{Kr}$ and $\mathrm{N}_{2}$ show simpler maxima between 950 and $1000 \mathrm{~cm}^{-1}$ above the $\mathrm{Q}_{\mathrm{X}}$ origin. The exact values depend on the host and the site but these maxima can be taken directly as the $\mathrm{Q}_{\mathrm{Y}}$ state origins. In contrast, excitation spectra in Xe show complex structures between $850 \mathrm{~cm}^{-1}$ and $950 \mathrm{~cm}^{-1}$. Obviously, this structure is the result of a more extensive coupling between the $\mathrm{Q}_{\mathrm{Y}}$ origin and the vibrationally excited levels of $\mathrm{Q}_{\mathrm{X}}$, involving a larger number of vibrational states as observed for neon.

In $\mathrm{Xe}$ the $\mathrm{b}_{1 \mathrm{~g}}$ mode of $\mathrm{Q}_{\mathrm{X}}$ around $889 \mathrm{~cm}^{-1}$ is close to resonance with the $\mathrm{Q}_{\mathrm{Y}}$ origin. One can notice that this particular mode is totally absent in emission spectra whereas it is observed in excitation in all the cases, including in the gas phase. Its intensity enhancement comes from the $\mathrm{Q}_{\mathrm{X}} / \mathrm{Q}_{\mathrm{Y}}$ state coupling. Table 5 reports the frequency values of the bands observed in excitation spectra in different hosts. Even when the values do not correspond to simple vibrational levels of $\mathrm{Q}_{\mathrm{X}}$, they are not very different from one host to another. This means that in all the cases, the same vibronic levels are involved in the $\mathrm{Q}_{\mathrm{X}} / \mathrm{Q}_{\mathrm{Y}}$ coupling, and that this coupling remains weak.

As the energy of the $\mathrm{Q}_{\mathrm{Y}}$ state also shifts for different sites within a given matrix, different modes can couple with different interaction strengths, producing quite distinct bandshapes. In Fig. 9 a detailed comparison of the band origin of the $\mathrm{Q}_{\mathrm{Y}}$ state of $\mathrm{H}_{2} \mathrm{Pc}$ in $\mathrm{Ne}$ and $\mathrm{N}_{2}$ is shown for spectrally well defined sites. The data is presented as the shift from the band origin of the $\mathrm{Q}_{\mathrm{X}}$ state and it is evident in the wider range scans presented in the lower panel, that the vibronic bands of the $Q_{X}$ state match exactly while the origins of the $Q_{Y}$ state differ by at least $10 \mathrm{~cm}^{-1}$. In the upper panel it is also very evident that the $\mathrm{Q}_{\mathrm{Y}}$ state structures are quite distinct in the two matrices. As shown on the upper left in Fig. 9 the two sites in Ne (labelled Red and Blue) are broad and appear as a pair of dominant bands, while the data shown for three sites in $\mathrm{N}_{2}$ are simpler, appearing as single dominant band. This contrasting behaviour is attributed to the different $\mathrm{Q}_{\mathrm{X}} / \mathrm{Q}_{\mathrm{Y}}$ state couplings which are energy dependent, as explained previously. The additional structure, clearly observed in excitation spectra of the most intense bands related to the $\mathrm{Q}_{\mathrm{Y}}$ state, can come from the usual mismatch between the family of sites selected through its emission frequency, i.e. by its $\mathrm{G}-\mathrm{Q}_{\mathrm{X}}$ transition energy, and families of sites selected on another electronic transition, such as the $\mathrm{G}_{-} \mathrm{Q}_{\mathrm{Y}}$ transition. In nitrogen matrices, where the main " $\mathrm{Q}_{\mathrm{Y}}$ " band origin shifts progressively from one site to another, a similar shift is also observed on some other bands (distinguished by a and $\mathrm{b}$ in Table 5): these bands probably correspond to stronger $\mathrm{Q}_{\mathrm{X}}-\mathrm{Q}_{\mathrm{Y}}$ vibronic coupling ( $\mathrm{Q}_{\mathrm{X}}$ vibrations of $\mathrm{b}_{1 \mathrm{~g}}$ symmetry).
The transition energies of the red and blue sites of $\mathrm{H}_{2} \mathrm{Pc}$ in neon differ by around $70 \mathrm{~cm}^{-1}$ in the $\mathrm{Q}_{\mathrm{x}}-\mathrm{G}$ band origins. With an additional shift of $10 \mathrm{~cm}^{-1}$ from one site to another, they differ by around $80 \mathrm{~cm}^{-1}$ in the $\mathrm{Q}_{\mathrm{Y}}$ state origins. In nitrogen matrices, the two extreme sites shown in Fig. 9 differ also by around $70 \mathrm{~cm}^{-1}$ in the $\mathrm{Q}_{\mathrm{X}}$ origins. However, due to an inverse trend in the $\mathrm{Q}_{\mathrm{X}}-\mathrm{Q}_{\mathrm{Y}}$ splittings, they differ by only around $40 \mathrm{~cm}^{-1}$ in $\mathrm{Q}_{\mathrm{Y}}$ origins. This inversion was observed, but more pronounced in the recent work by Arabei et al. ${ }^{35}$ on methylated dibenzoporphin and was attributed to the different interactions between $\mathrm{N}-\mathrm{H} \mathrm{H}-\mathrm{N}$ bonds and the lattice. This interaction is weaker in neon than in nitrogen. The observed inversion in nitrogen explains also a narrower $\mathrm{Q}_{\mathrm{Y}}$ band than $\mathrm{Q}_{\mathrm{X}}$ in absorption (see Fig. 2).

3. Effect of isotope substitution on the $Q_{X} / Q_{Y}$ state couplings. The present analysis allows some comments to be made of the previous matrix study of $\mathrm{H}_{2} \mathrm{Pc}$ in argon reported by Bondybey and English. ${ }^{18}$ First of all, the polarisation behaviour of the excitation bands these authors present is in perfect agreement with the present assignments of the bands in terms of symmetries deduced from DFT calculations. Thus the $\mathrm{a}_{\mathrm{g}}$ vibrational modes are observed ${ }^{18}$ as parallel polarised bands while the $b_{1 \mathrm{~g}}$ modes are the perpendicular bands. These authors also identified an important deuteration effect in the excitation spectra of $\mathrm{H}_{2} \mathrm{Pc}$ and $\mathrm{D}_{2} \mathrm{Pc}$ in argon. The intense band assigned to the origin of the $\mathrm{Q}_{\mathrm{Y}}$ electronic transition at $983 \mathrm{~cm}^{-1}$ (from the $0-0$ of the $\mathrm{Q}_{\mathrm{X}}-\mathrm{G}$ transition) in $\mathrm{H}_{2} \mathrm{Pc}$ was seen to be replaced by a complex structure with the most intense part, shifted down by $37 \mathrm{~cm}^{-1}$ to $946 \mathrm{~cm}^{-1}$ in $\mathrm{D}_{2} \mathrm{Pc}$. From our DFT results, ${ }^{24}$ it is known that $b_{1 \mathrm{~g}}$ modes located between $800 \mathrm{~cm}^{-1}$ and $1100 \mathrm{~cm}^{-1}$ are those exhibiting the most pronounced isotopic effect, because they involve NH in-plane bending motions. In particular, the $1026 \mathrm{~cm}^{-1}$ mode (Raman value) appearing in the excitation spectra of $\mathrm{H}_{2} \mathrm{Pc}$ around $1030 \mathrm{~cm}^{-1}$ in all the matrices, shifts to $986 \mathrm{~cm}^{-1}$ (Raman value) in $\mathrm{D}_{2} \mathrm{Pc}$. The corresponding $\mathrm{D}_{2} \mathrm{Pc}$ unperturbed vibrational level at $987.12 \mathrm{~cm}^{-1}$ (scaled DFT Raman value) should, as shown on the right in Fig. 10 be in perfect resonance with the $\mathrm{Q}_{\mathrm{Y}}$ origin in Ar, following our previous assignment in $\mathrm{H}_{2} \mathrm{Pc}$. The consequent strong $\mathrm{Q}_{\mathrm{X}} / \mathrm{Q}_{\mathrm{Y}}$ interaction could explain the observed feature in $\mathrm{D}_{2} \mathrm{Pc} / \mathrm{Ar}$ samples with two intense bands distributed below and above the $\mathrm{H}_{2} \mathrm{Pc} \mathrm{Q}_{\mathrm{Y}}$ origin energy.

The intense band shown in Fig. 8 at $882 \mathrm{~cm}^{-1}$ in the Ar excitation spectra ( $889 \mathrm{~cm}^{-1}$ Raman value) is considerably weaker in $\mathrm{D}_{2} \mathrm{Pc}$. The corresponding $\mathrm{D}_{2} \mathrm{Pc}$ Raman value is calculated at $747 \mathrm{~cm}^{-1}$ but was not observed. This $\mathrm{D}_{2} \mathrm{Pc}$ value, far from the expected $\mathrm{Q}_{\mathrm{X}}-\mathrm{Q}_{\mathrm{Y}}$ splitting in Ar, could explain its loss of activity through the vibronic $\mathrm{Q}_{\mathrm{X}} / \mathrm{Q}_{\mathrm{Y}}$ interaction. These modes involve a $\mathrm{N}-\mathrm{H}(\mathrm{D})$ bending motion coupled to the bridging atoms $\mathrm{C}-\mathrm{N}-\mathrm{C}$ and peripheral aryl $\mathrm{C}-\mathrm{C}-\mathrm{C}$ atoms. Accordingly, it is not surprising that such modes are important in the $Q_{X} / Q_{Y}$ coupling. Other modes at higher energies than the $Q_{Y}$ state were also noticed to shift upon deuteration but due to the complex overlap of $\mathrm{Q}_{\mathrm{X}}$ and $\mathrm{Q}_{\mathrm{Y}}$ vibronic bands in this region, assignments are not straightforward. No isotopic dependence was seen for the vibronic bands in the excitation spectra up to and including the mode at $795 \mathrm{~cm}^{-1}$ from the $\mathrm{Q}_{\mathrm{X}}$ state band origin. 


\section{Conclusions}

We have investigated the electronic spectra of two tetrapyrrolic molecules isolated in rare gas and nitrogen matrices, namely free-base phthalocyanine and zinc phthalocyanine. A comparison of the Raman and fluorescence spectra for both molecules reveals striking similarities, not only in the band positions but also in the intensities. This behaviour is explained by the selection rules pertaining for both types of transitions in these planar molecules. This allowed the use of the assigned Raman active modes, calculated for the ground electronic state with large basis set, density functional theory, to identify the vibronic modes present in emission for $\mathrm{H}_{2} \mathrm{Pc}$ and $\mathrm{ZnPc}$. The observed vibronic frequencies in the ground $(\mathrm{G})$ and first excited $(\mathrm{Q})$ states of $\mathrm{ZnPc}$ were found to be very similar. This indicates a very similar geometry in the excited state to that in the ground state and allowed the vibrational modes in the $\mathrm{Q}$ state to be assigned using the DFT calculated Raman spectra. In the case of $\mathrm{H}_{2} \mathrm{Pc}$, the existence of the second excited $\mathrm{Q}_{\mathrm{Y}}$ state only $1000 \mathrm{~cm}^{-1}$ above $\mathrm{Q}_{\mathrm{X}}$ is responsible for the observation of a very complicated excitation spectrum due to coupling between the band origin of the $\mathrm{Q}_{\mathrm{Y}}\left(\mathrm{S}_{2}\right)$ electronic state and vibrational levels of the $\mathrm{Q}_{\mathrm{X}}\left(\mathrm{S}_{1}\right)$ state. This made assignment of the modes above the $\mathrm{Q}_{\mathrm{Y}}$ more difficult using the ground state vibrational modes observed in emission or Raman spectra.

The energy difference between the $\mathrm{QX}_{\mathrm{X}}$ and $\mathrm{Q}_{\mathrm{Y}}$ states of $\mathrm{H}_{2} \mathrm{Pc}$ was found to be dependent on the host matrix, with the largest $\mathrm{Q}_{\mathrm{X}}-\mathrm{Q}_{\mathrm{Y}}$ splitting of $1017 \mathrm{~cm}^{-1}$ found in $\mathrm{Ne}$ and the smallest splitting of $916 \mathrm{~cm}^{-1}$ in Xe (mean values from absorption spectra). Consequently, the excitation spectra of $\mathrm{H}_{2} \mathrm{Pc}$ strongly differ in band structures and energy distribution in the spectral range of the $\mathrm{Q}_{\mathrm{Y}}$ origin from one host to the other and even from one trapping site to another in the same host. The non-adiabatic coupling of this band with fundamental $b_{1 \mathrm{~g}}$ modes of $\mathrm{Q}_{\mathrm{X}}$ involving in-plane $\mathrm{NH}$ bending motions seems to be specifically important. Such couplings also explain the deuteration effect observed by Bondybey et al. ${ }^{18}$ on the excitation spectra of the free-base phthalocyanines. Further analysis, including more extensive experimental analysis and theoretical calculations, is required in order to fully resolve the vibrational modes coupling in both excited states of $\mathrm{H}_{2} \mathrm{Pc}$ and in various host environments.

\section{Acknowledgements}

This work was supported by the Ulysses France-Ireland research exchange grants (2006 and 2011) and the Science Foundation Ireland (SFI), Research Frontiers Programme (06/RFP/CHP012) Grant. The authors wish to acknowledge fruitful discussions with Professor S.M. Arabei.

\section{References}

1 F. M. Moser and A. L. Thomas, Phthalocyanine Compounds, Reinhold Publishing corporation, New-York, 1969.

2 T. Hanada, H. Takiguchi, Y. Okada, Y. Yoshida, N. Tanigaki and K. Yase, J. Cryst. Growth, 1999, 204(3), 307.
3 J. L. Bredas, C. Adant, P. Tackx and A. Persoons, Chem. Rev., 1994, 94(1), 243.

4 D. Eastwood, L. Edwards, M. Gouterman and J. Steinfeld, J. Mol. Spectrosc., 1966, 20(4), 381.

5 L. Edwards and M. Gouterman, J. Mol. Spectrosc., 1970, 33, 292.

6 F. L. Plows and A. C. Jones, J. Mol. Spectrosc., 1999, 194(2), 163.

7 P. S. H. Fitch, Ch. A. Hayman and D. H. Levy, J. Chem. Phys., 1980, 73, 1064

8 P. S. H. Fitch, Ch. A. Hayman and D. H. Levy, J. Chem. Phys., 1981, 74, 6612.

9 A. Slenczka, B. Dick, M. Hartmann and J. P. Toennies, J. Chem. Phys., 2001, 115, 10199; M. Hartmann, A. Lindinger, J. P. Toennies and A. F. Vilesov, Phys. Chem. Chem. Phys., 2002, 4, 4839; R. Lehnig, J. Sebree and A. Slenczka, J. Phys. Chem. A, 2007, 111, 7576.

10 R. Lehnig and A. Slenczka, J. Chem. Phys., 2003, 118, 8256; R. Lehnig and A. Slenczka, J. Chem. Phys., 2004, 120, 5064; R. Lehnig, M. Slipchenko, S. Kuma, T. Momose, B. Sartakov and A. Vilesov, J. Chem. Phys., 2004, 121, 9396.

11 A. Stendal, U. Beckers, S. Wilbrandt, O. Stenzel and C. von Borczyskowski, J. Phys. B: At., Mol. Opt. Phys., 1996, 29, 2589.

12 J. Hala, I. Pelant, L. Parma and K. Vacek, Czech. J. Phys., 1982, 32, 705 .

13 T.-H. Huang, K. E. Rieckhoff and E. M. Voigt, J. Chem. Phys., 1982, 77, 3424

14 R. I. Personov, Opt. Spectrosc., 1963, 15, 30.

15 P. Geissinger and D. Haarer, Chem. Phys. Lett., 1992, 197, 175.

16 B. J. Prince, B. E. Williamson and R. J. Reeves, J. Lumin., 2001, 93, 293.

17 L. Bajema, M. Gouterman and B. Meyer, J. Mol. Spectrosc., 1968, 27, 225.

18 V. E. Bondybey and J. H. English, J. Am. Chem. Soc., 1979, 101, 3446.

19 D. H. Metcalf, T. C. vanCott, S. W. Snyder, P. N. Schatz and B. E. Williamson, J. Phys. Chem., 1990, 94, 2828.

20 R. Aroca, D. P. DiLella and R. O. Loutfi, J. Phys. Chem. Solids, 1982, 43, 707.

21 D. R. Tackley, G. Dent and W. E. Smith, Phys. Chem. Chem. Phys., 2001, 3, 1419.

22 D. R. Tackley, G. Dent and W. E. Smith, Phys. Chem. Chem. Phys., 2000, 2, 3949.

$23 \mathrm{X}$. Zhang, Y. Zhang and J. Jiang, Vib. Spectrosc., 2003, 33(1-2), 153.

24 C. Murray, N. Dozova, S. FitzGerald, J. G. McCaffrey, N. Shafizadeh and C. Crépin, Phys. Chem. Chem. Phys., 2010, 12, 10406.

25 S. G. Bown, C. J. Tralau, P. D. Coleridge Smith, D. Akdemir and T. J Wieman, Br. J. Cancer, 1986, 54(1), 43.

26 P. Geissinger, L. Kaldor and D. Haarer, Phys. Rev. B: Condens. Matter, 1996, 53, 4356.

27 N. Dozova, C. Murray, J. G. McCaffrey, N. Shafizadeh and C. Crépin, Phys. Chem. Chem. Phys., 2008, 10, 2167.

28 C. Crépin, N. Shafizadeh, W. Chin, J.-P. Galaup, J. G. McCaffrey and S. M. Arabei, Low Temp. Phys., 2010, 36, 451.

29 M. A. Collier and J. G. McCaffrey, J. Chem. Phys., 2005, 122, 184507

30 C. Gée, A. Cuisset, L. Divay and C. Crépin, J. Chem. Phys., 2002, 116, 4993.

31 J. G. Radziszewski, J. Waluk and J. Michl, Chem. Phys., 1989, 136, 165.

32 U. Even, J. Magen, J. Jortner, J. Friedman and H. Levanon, J. Chem. Phys., 1982, 77, 4374.

33 S. M. Arabei, V. A. Kuzmitsky and K. N. Solovyov, Opt. Spectrosc., 2007, 102, 692.

34 S. M. Arabei, K. N. Solovev and Yu. I. Tatulchenkov, Opt. Spectrosc., 1992, 73, 406.

35 S. M. Arabei, V. A. Kuzmitsky and K. N. Solovyov, Chem. Phys., 2008, 352, 197. 